\title{
Aminimide Synthesis Using Concerted Amination Reactions of Alkenes: Scope and Mechanistic Information
}

Ryan A. Ivanovich $\dagger$, Jasper A. M. Quartus $\dagger$, Nicolas Das Neves, Francis Loiseau, Michael Raymond, André M. Beauchemin*

Centre for Catalysis Research and Innovation, Department of Chemistry and Biomolecular Sciences, University of Ottawa, 10 Marie-Curie, Ottawa, ON, K1N 6N5, Canada

Supporting Information

Table of contents

Spectra

NOESY S36 

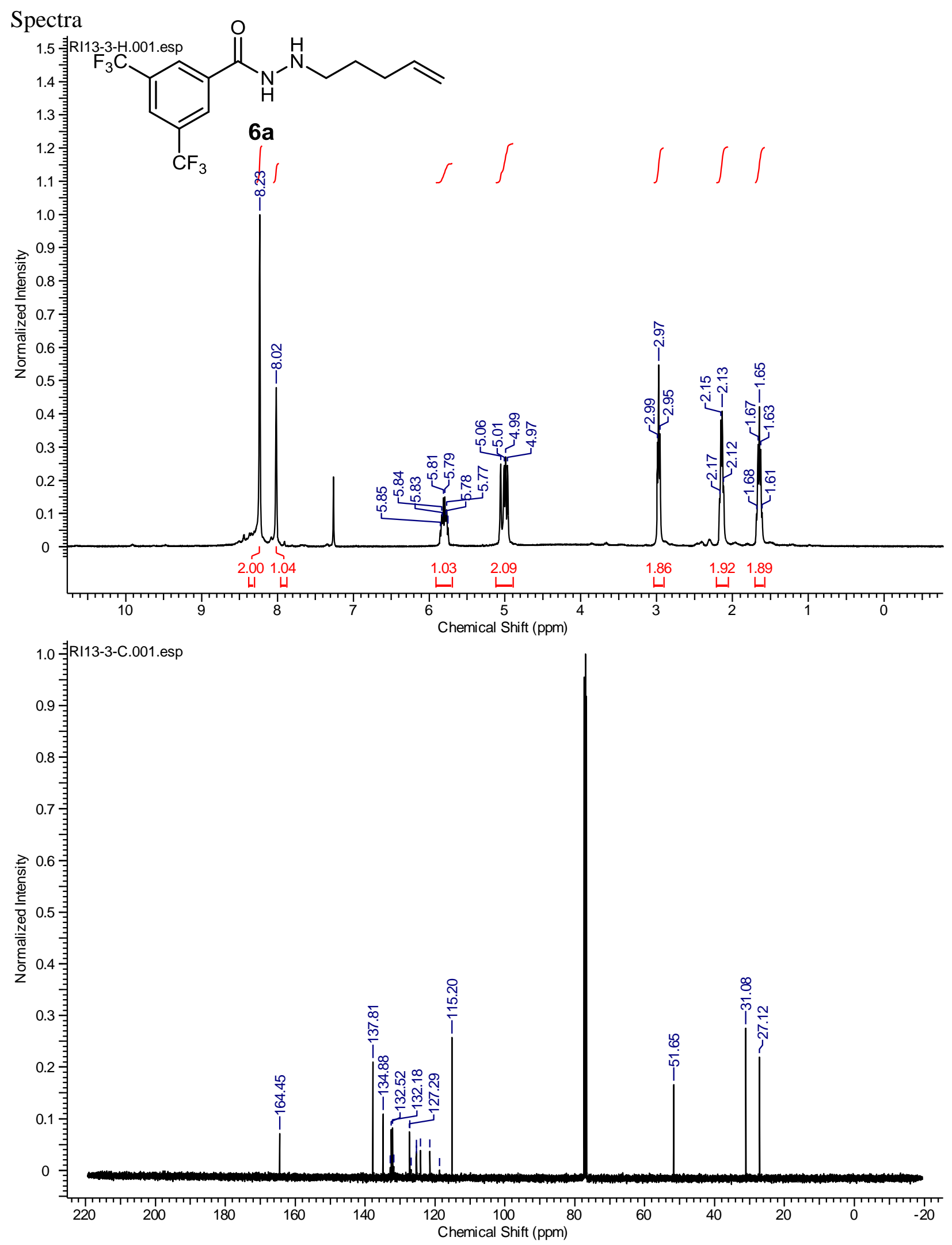


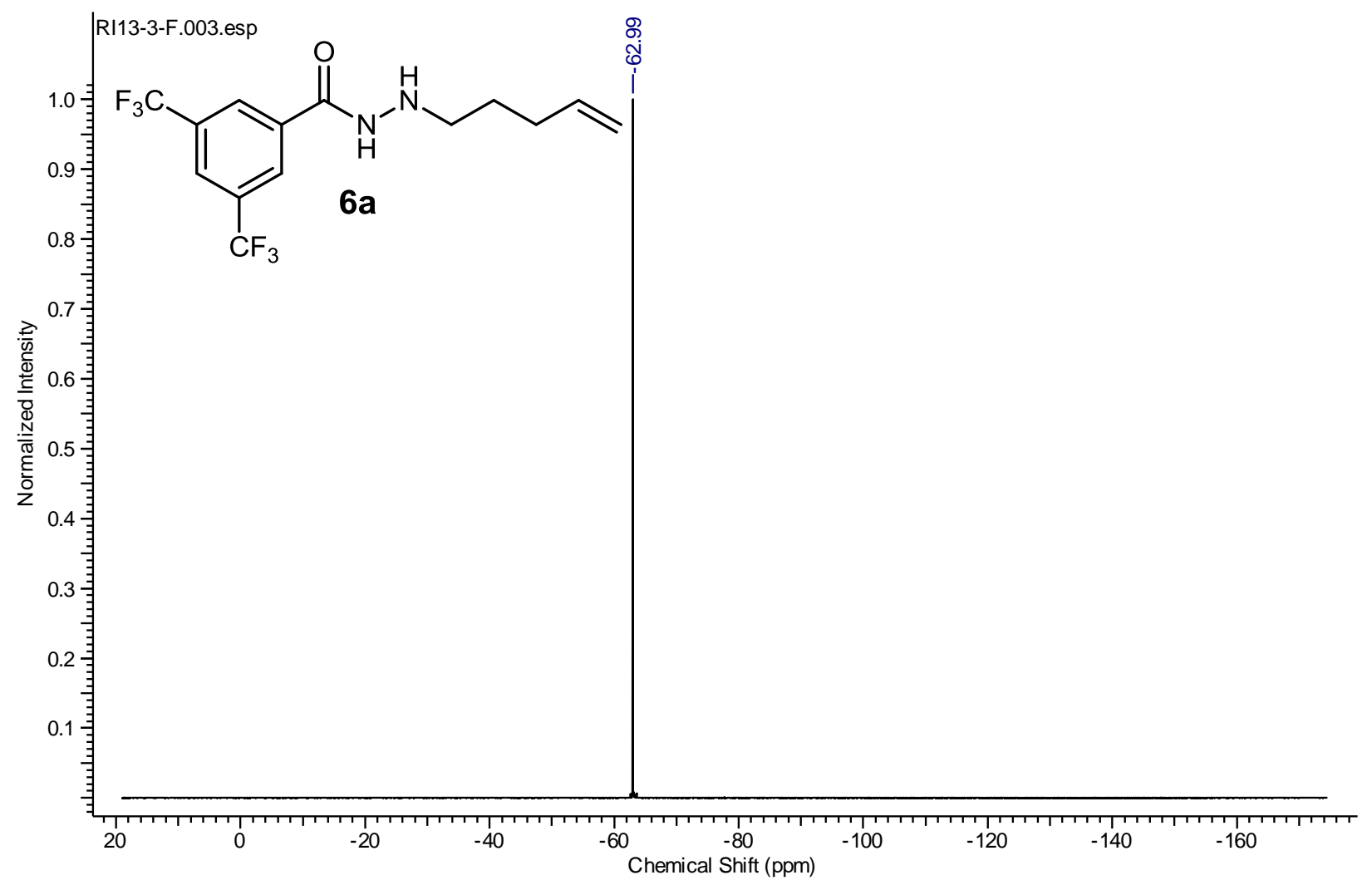



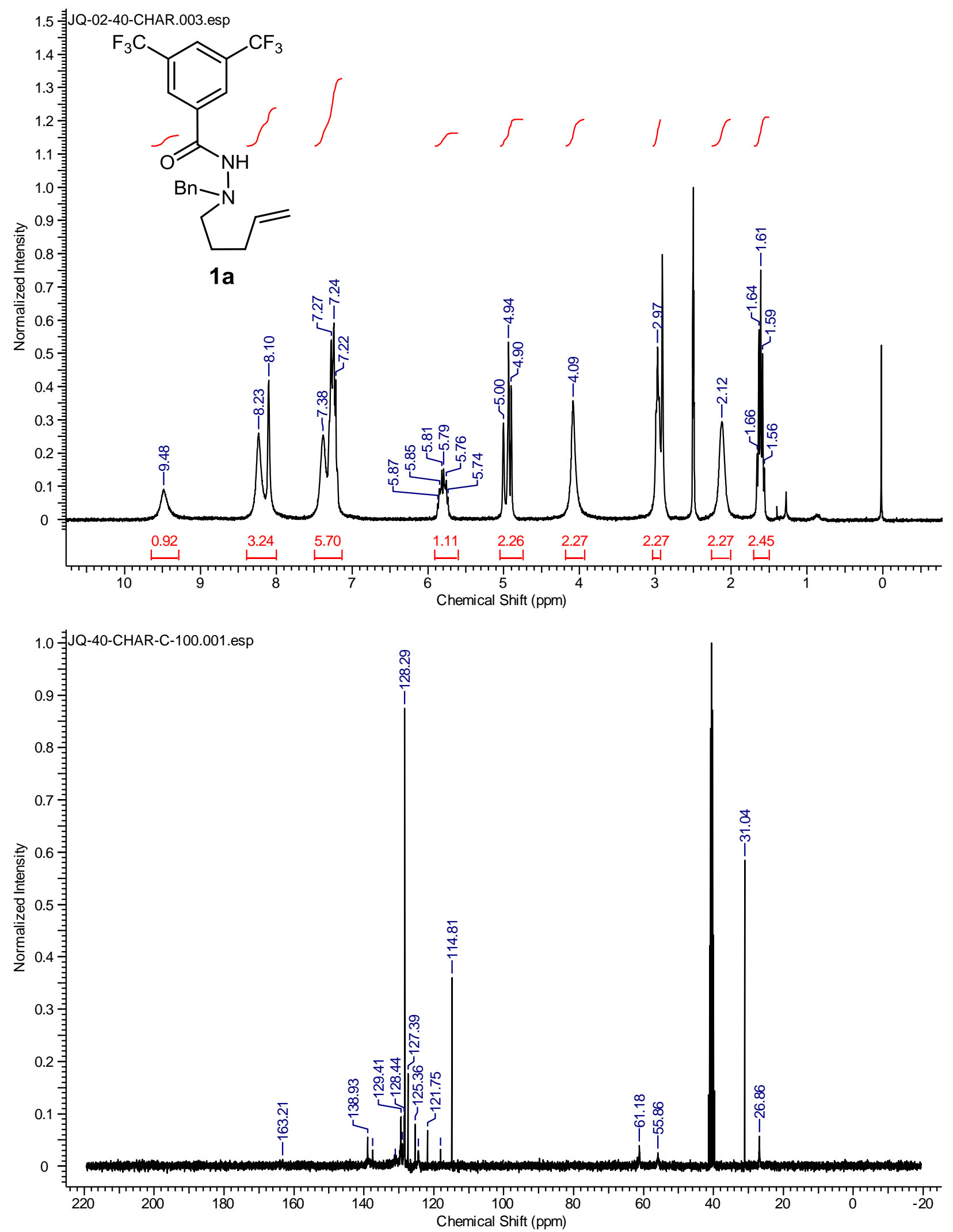


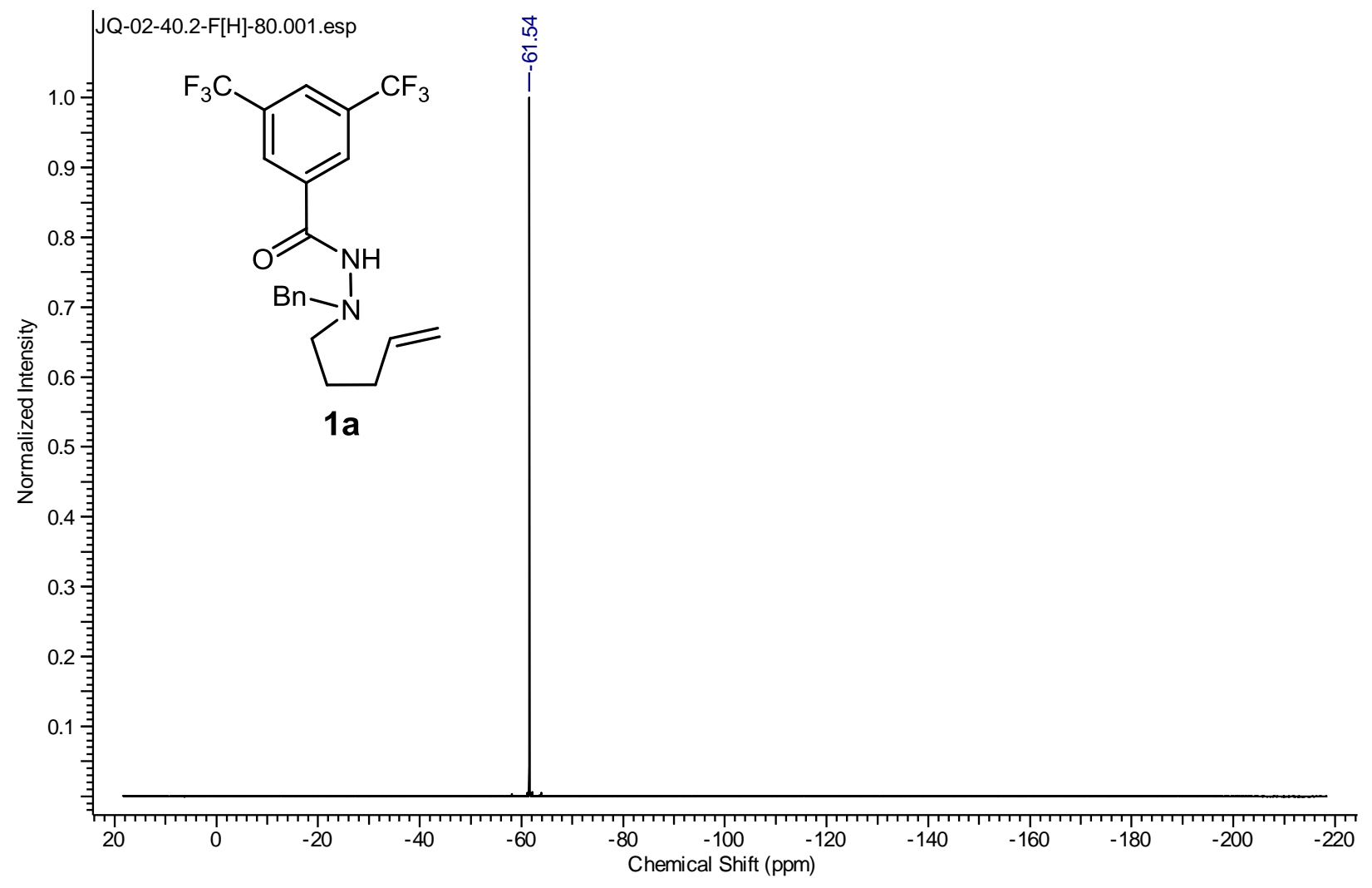



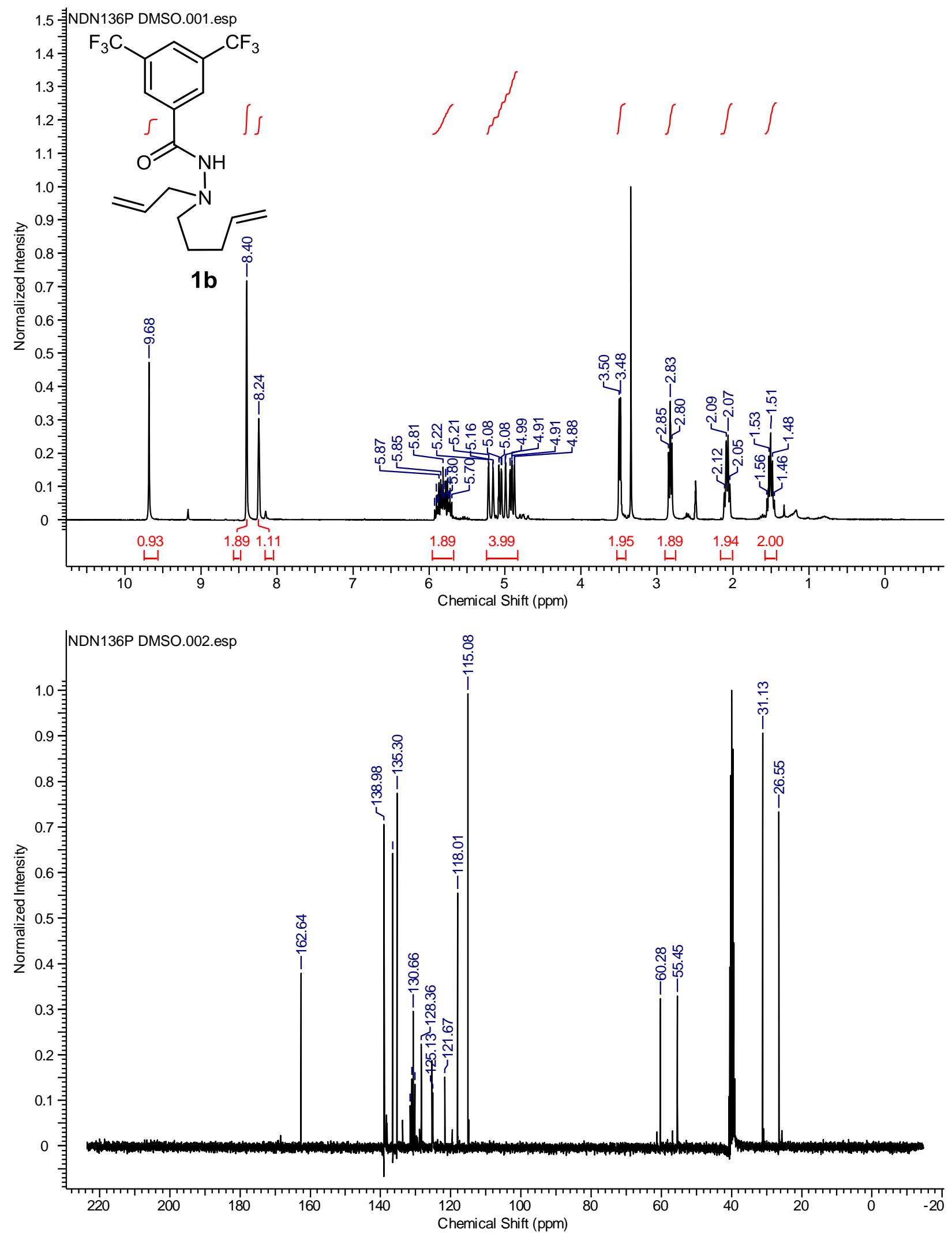


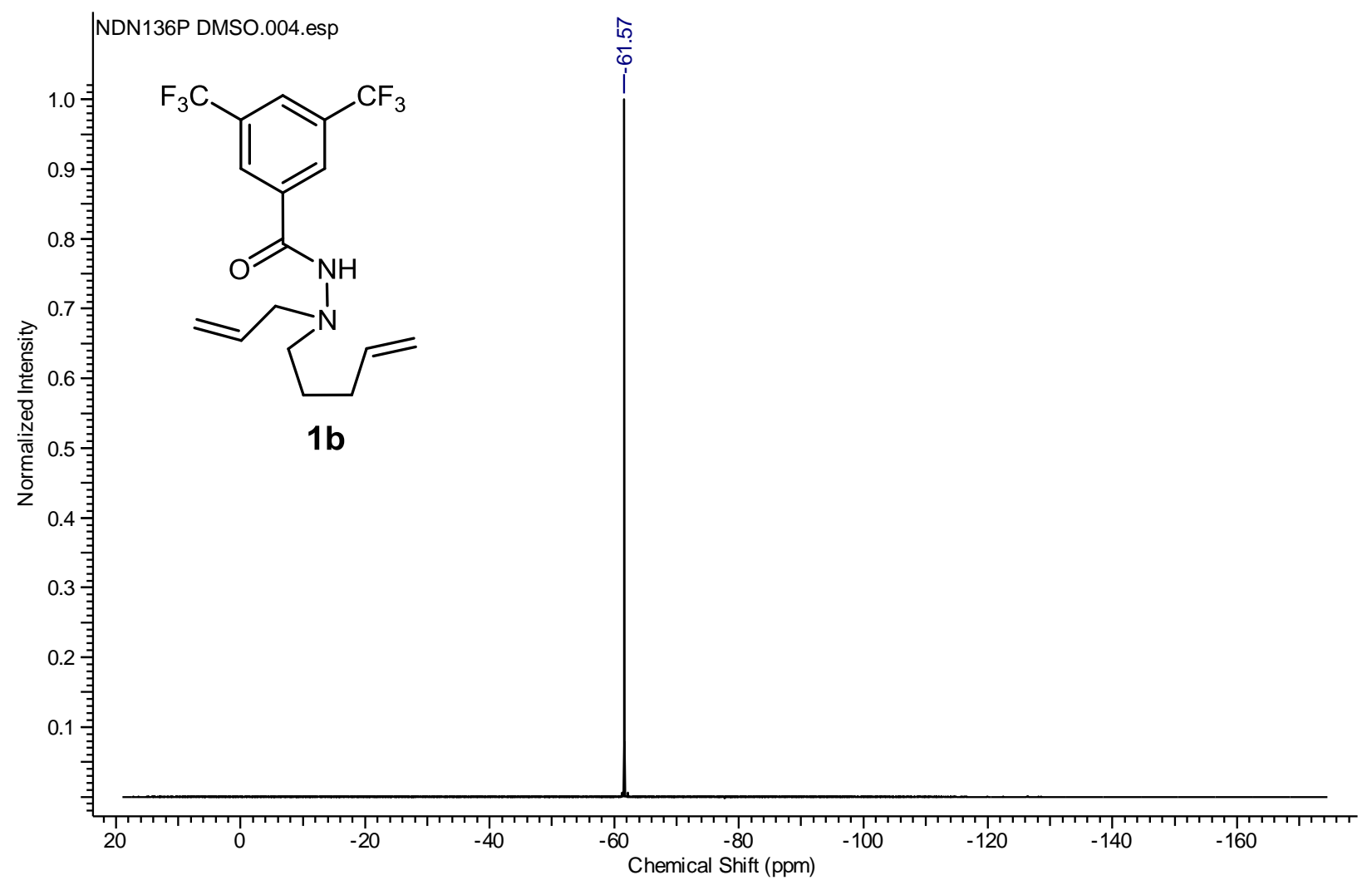



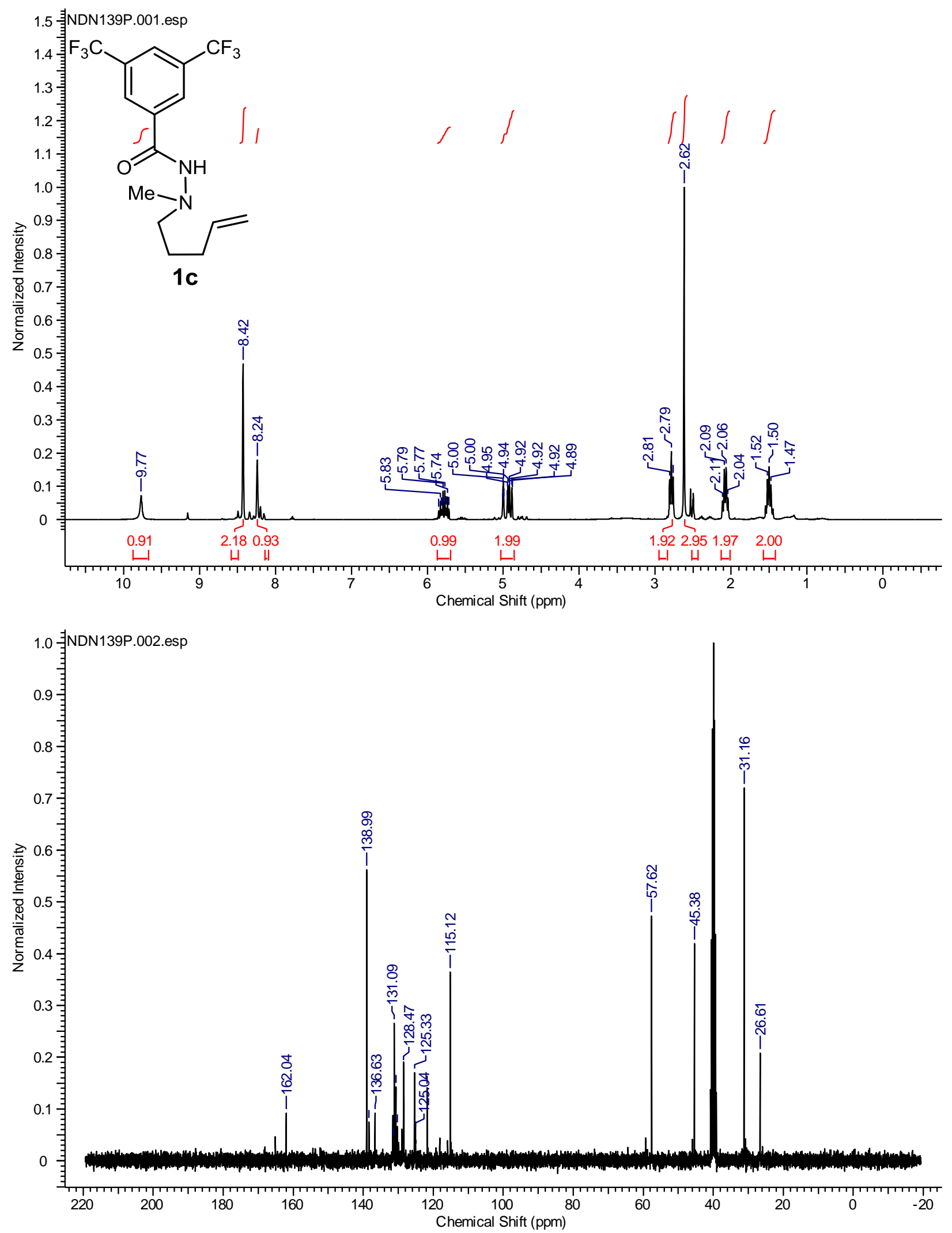


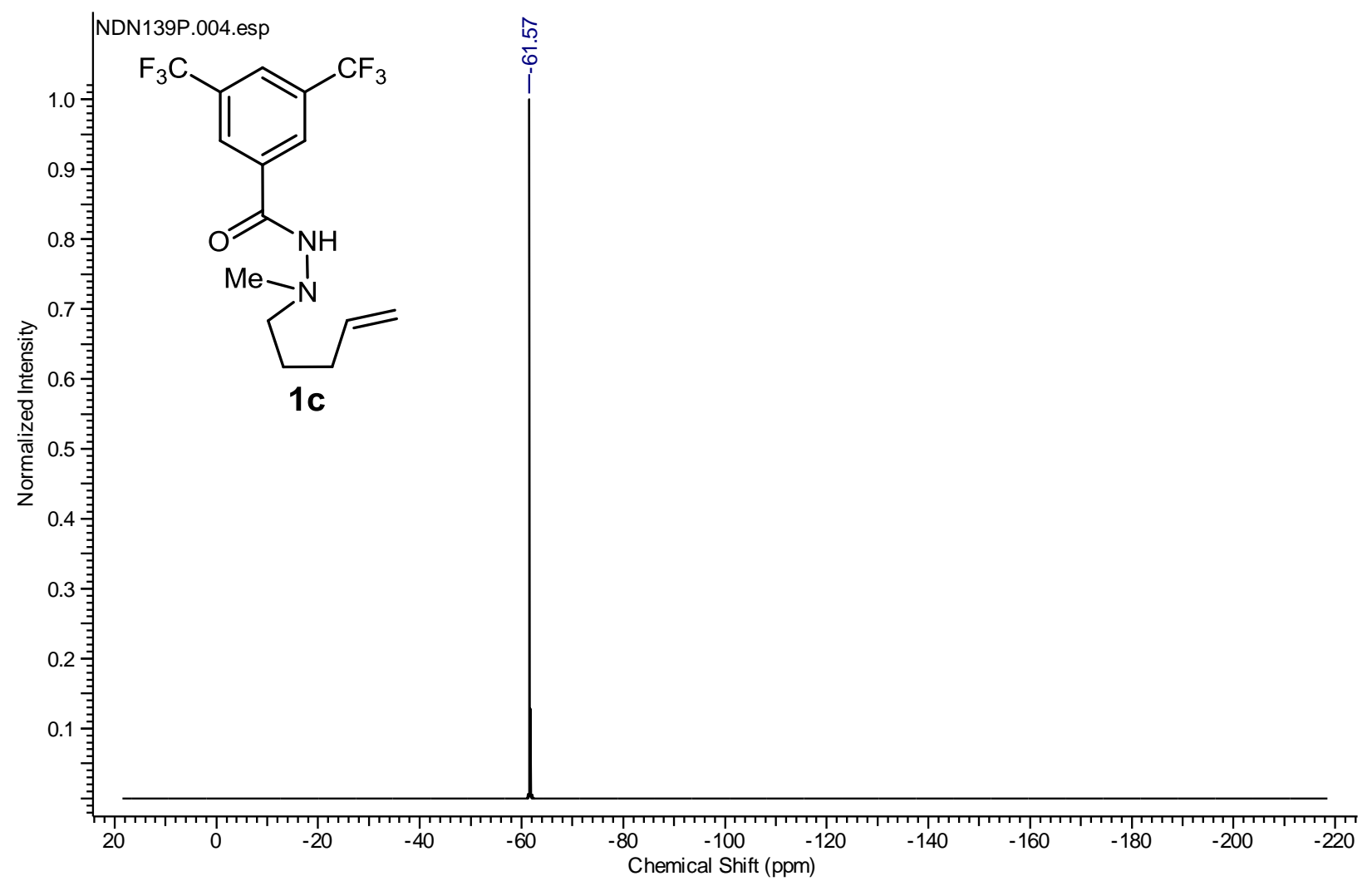



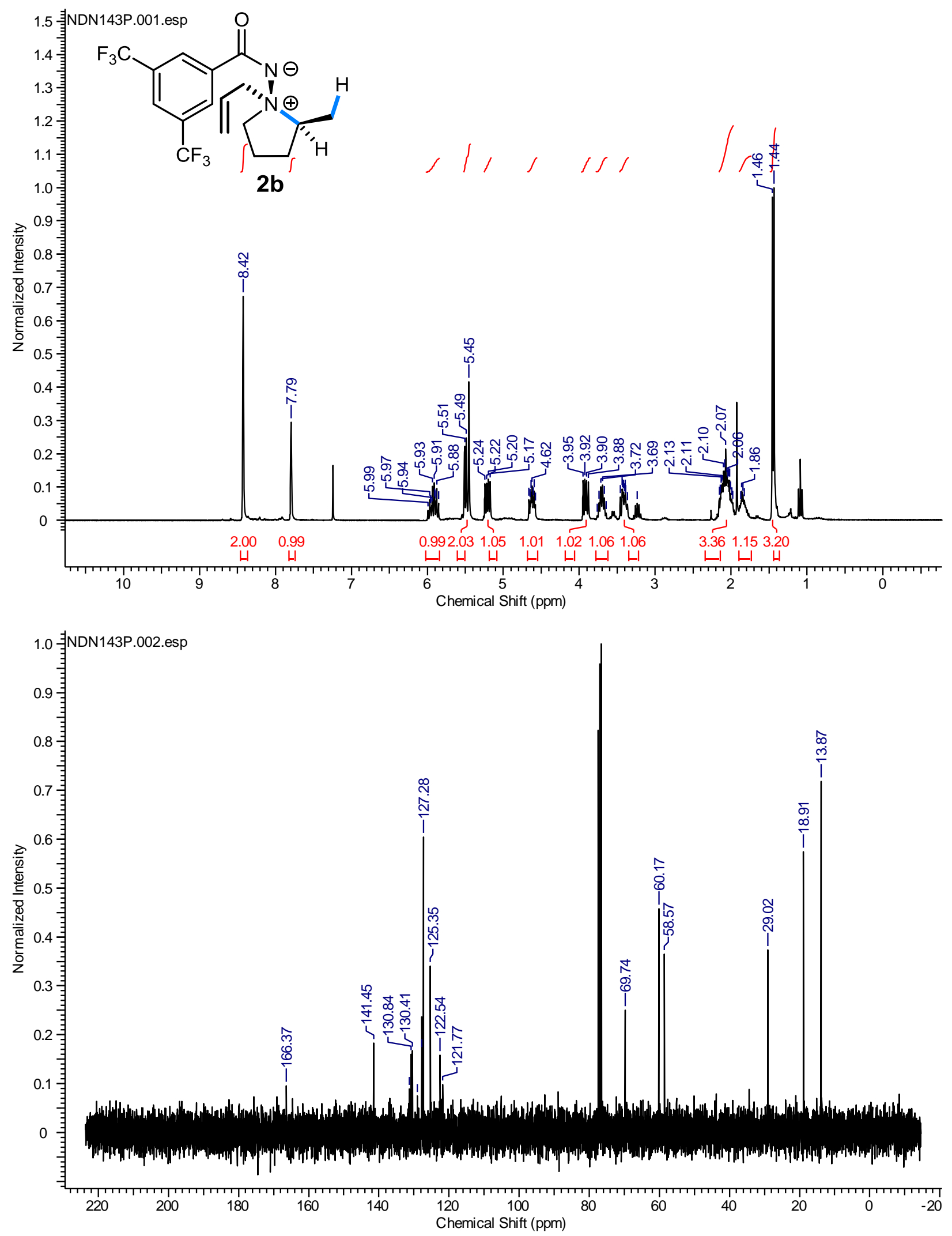


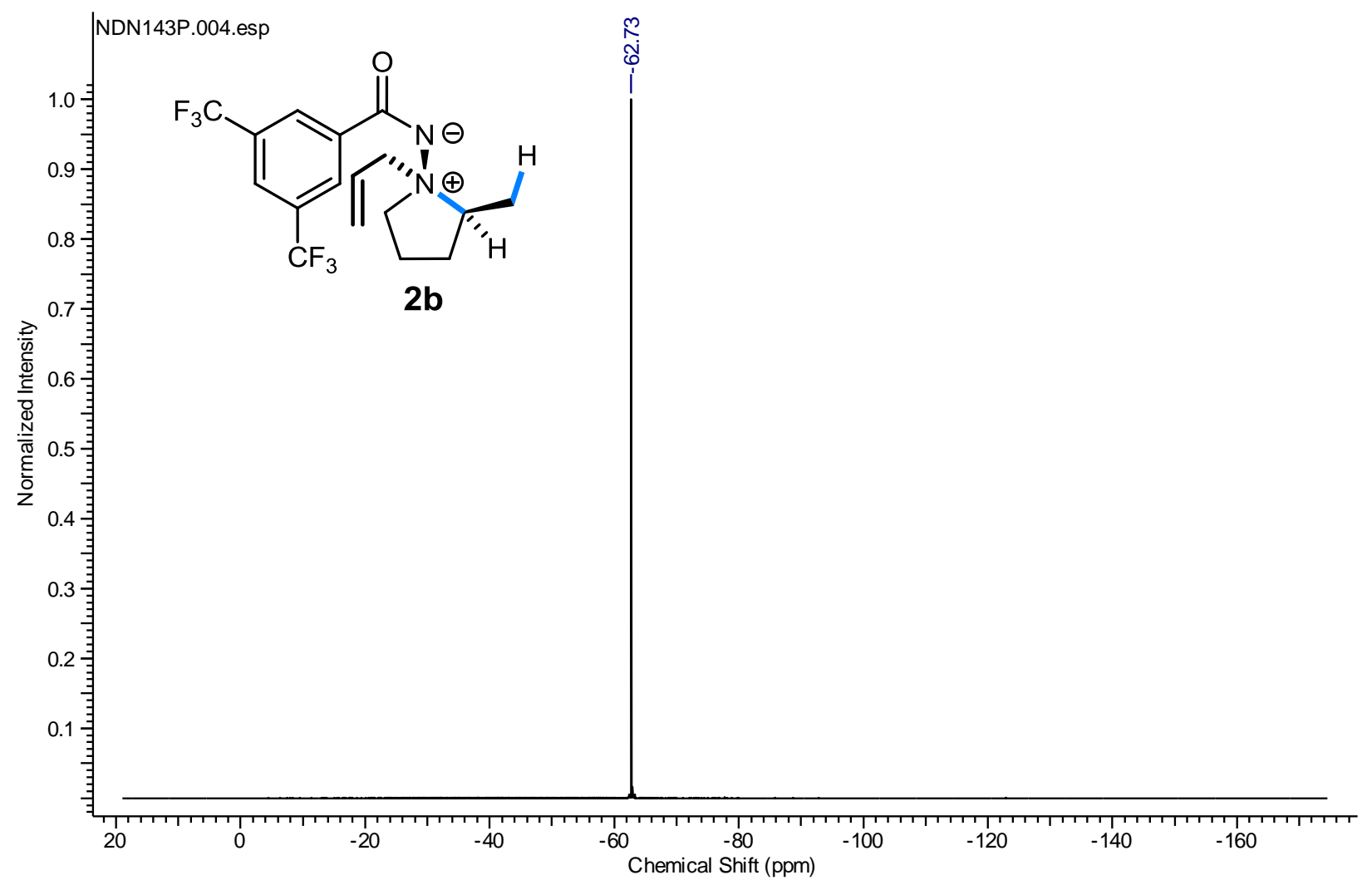



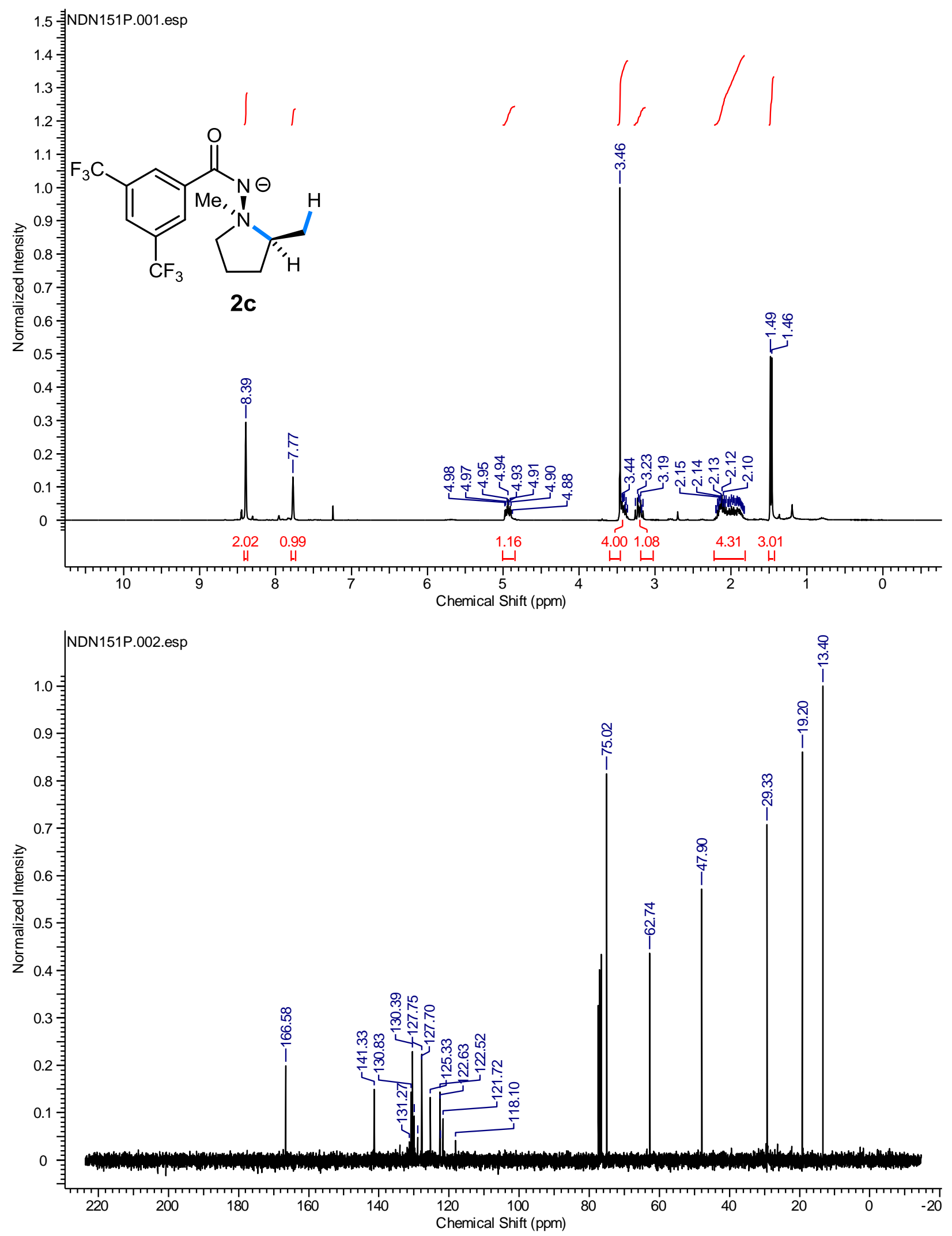


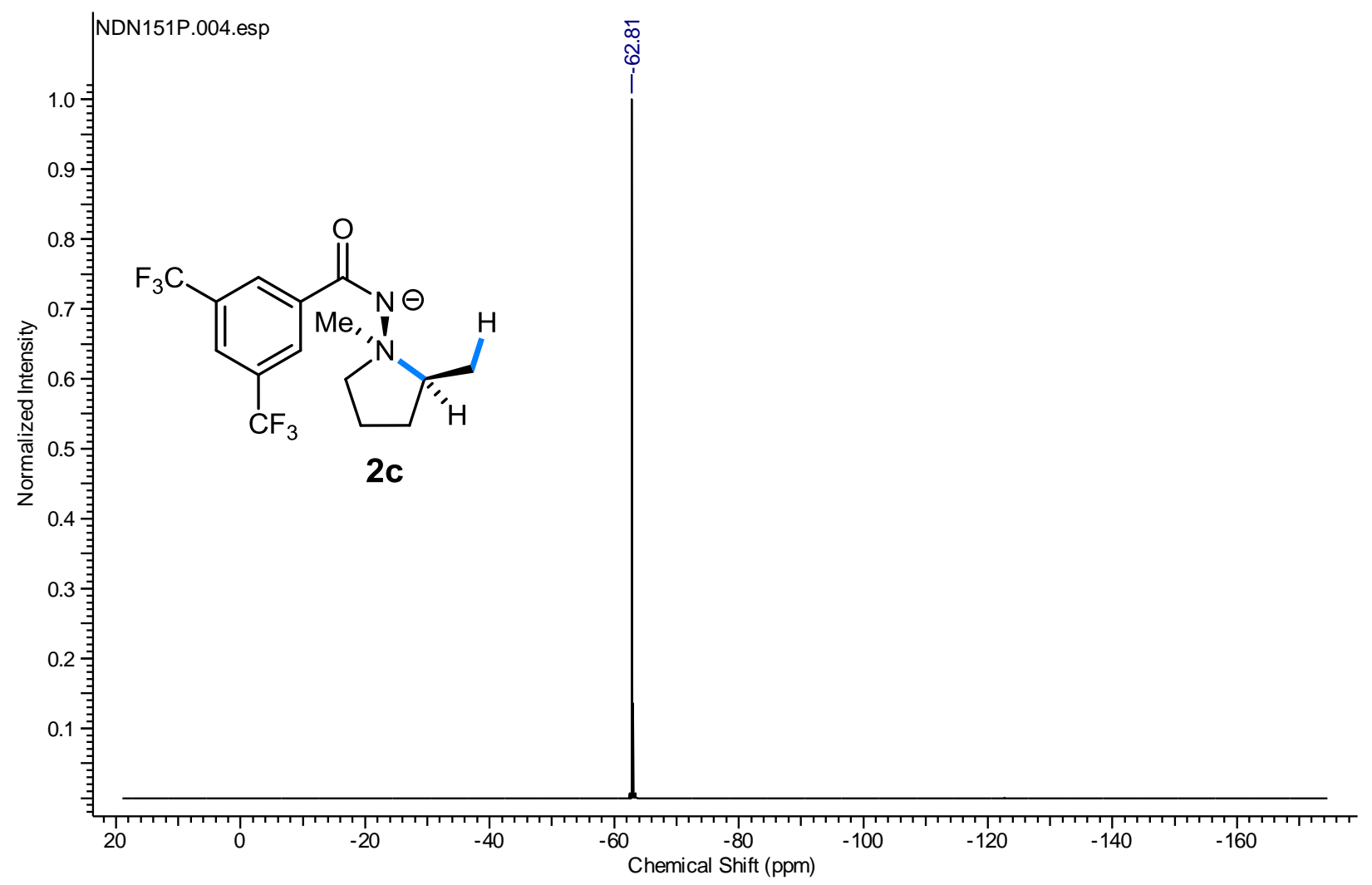



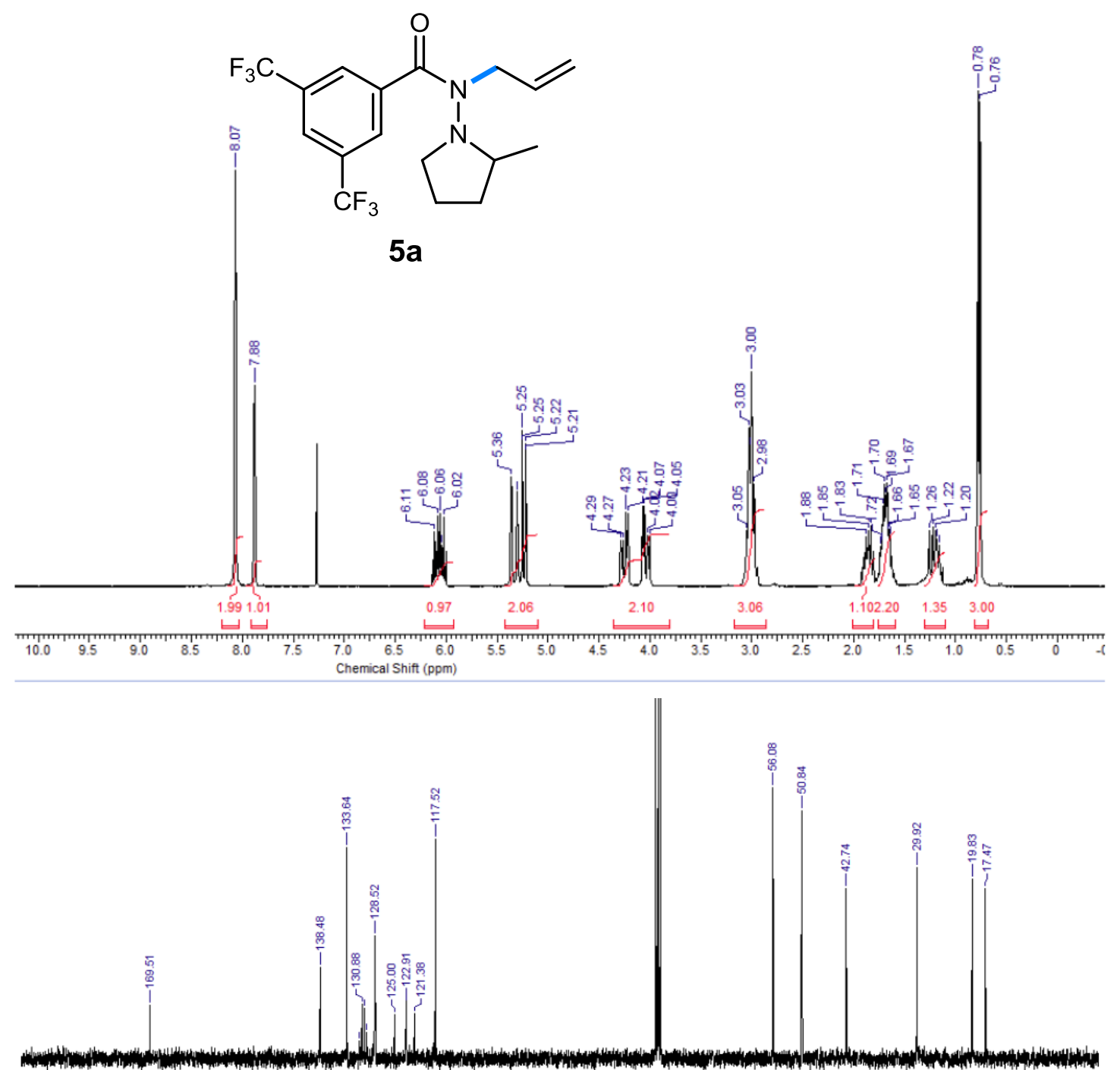

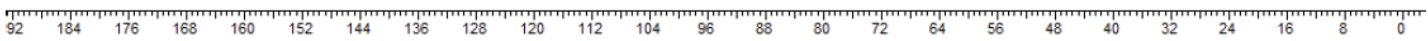

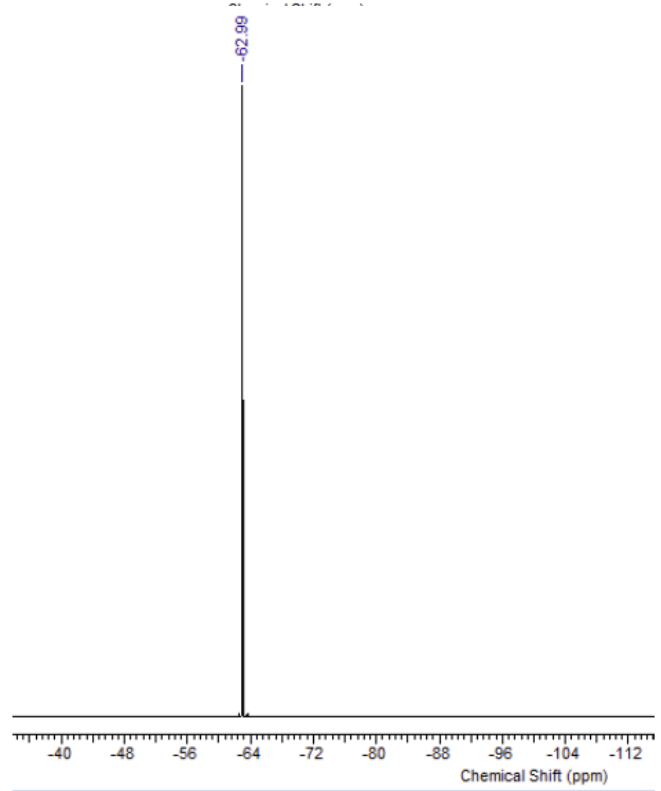



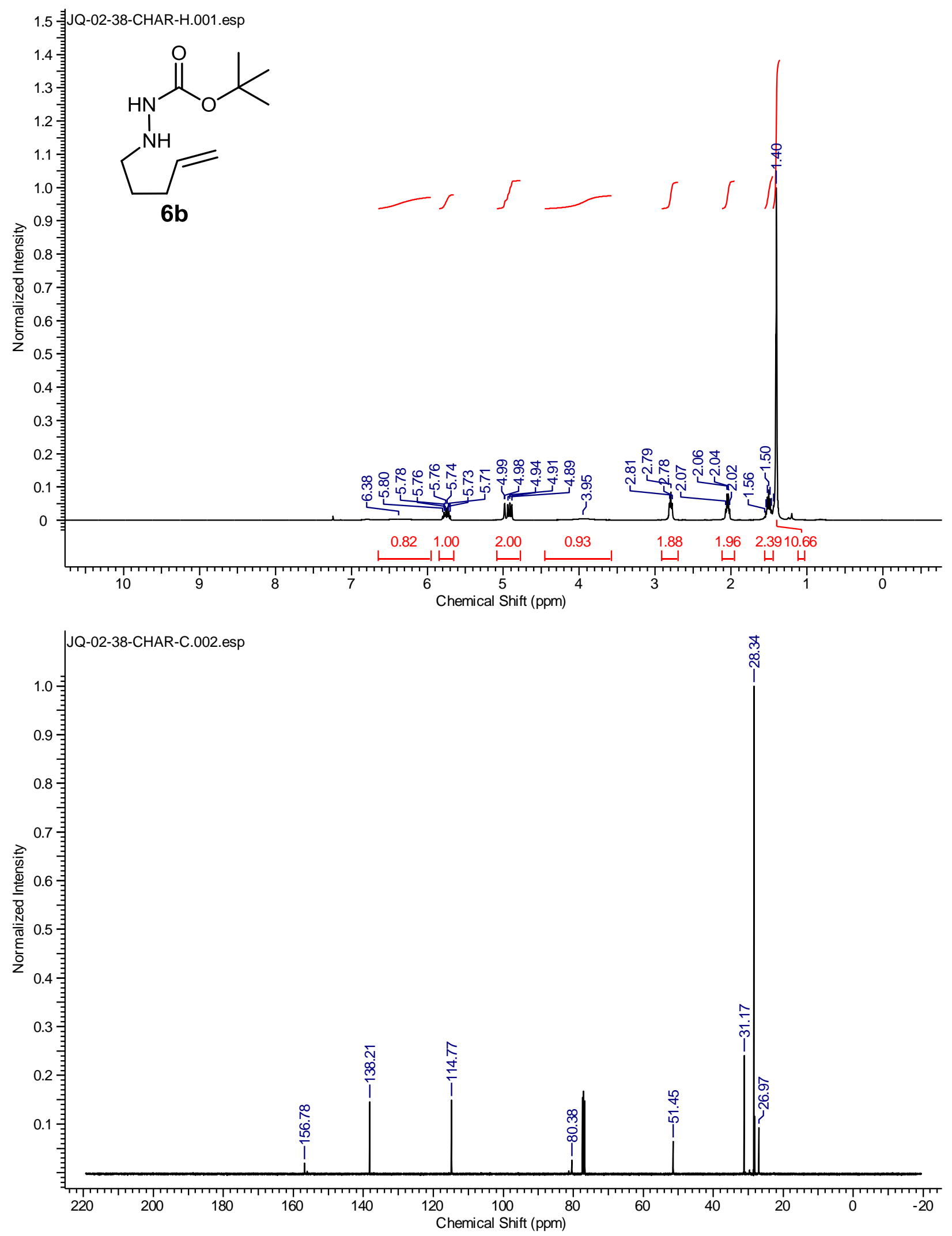

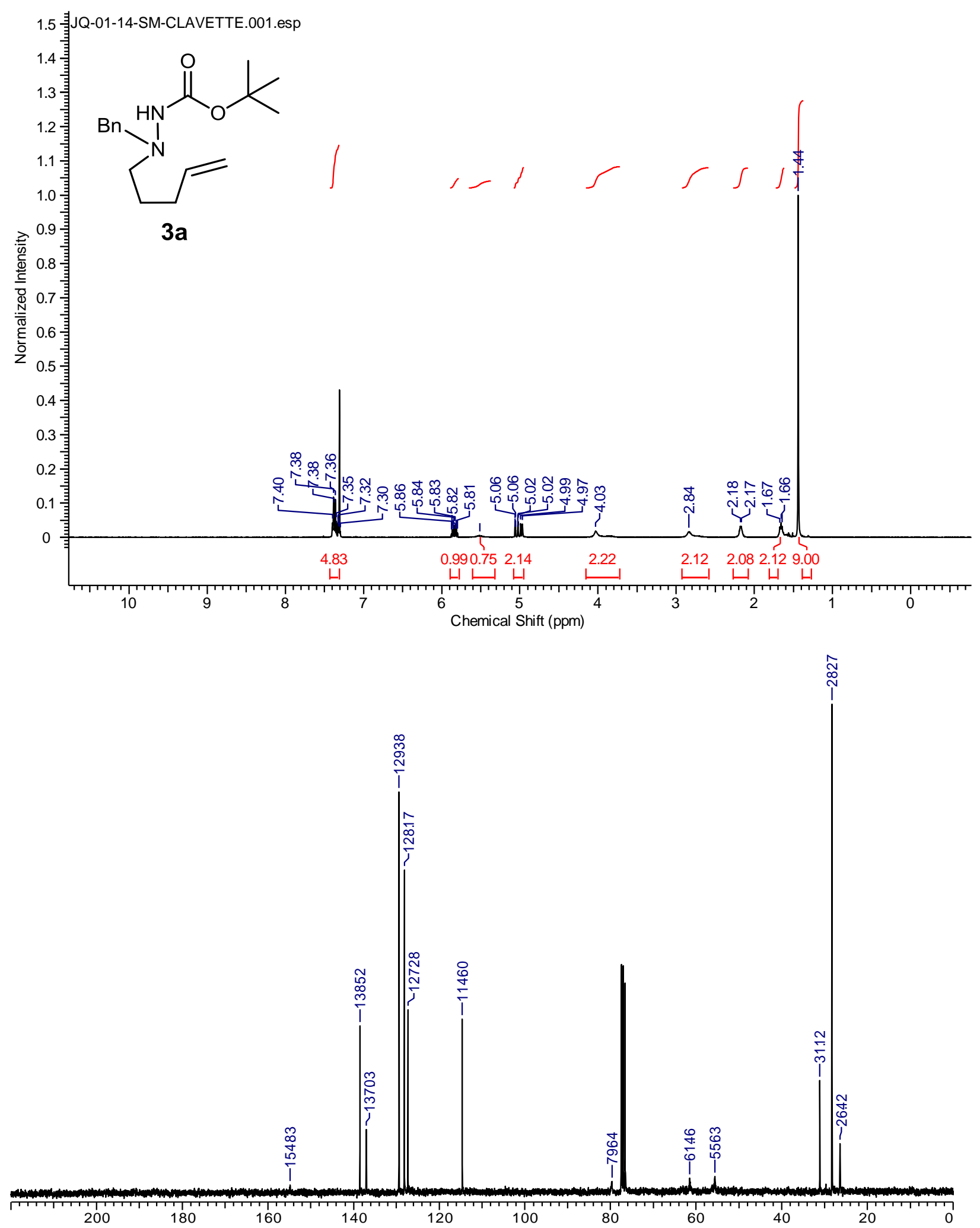

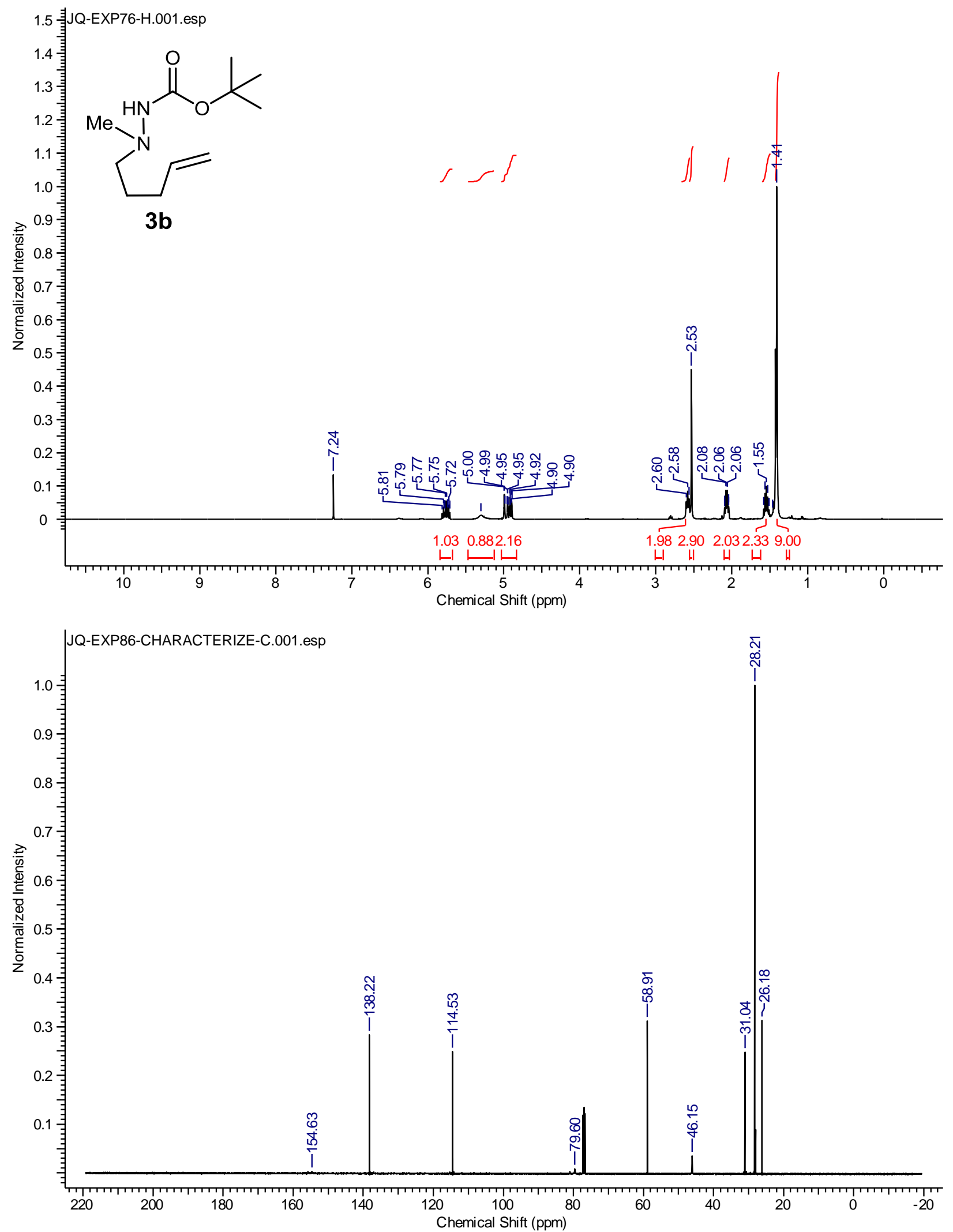

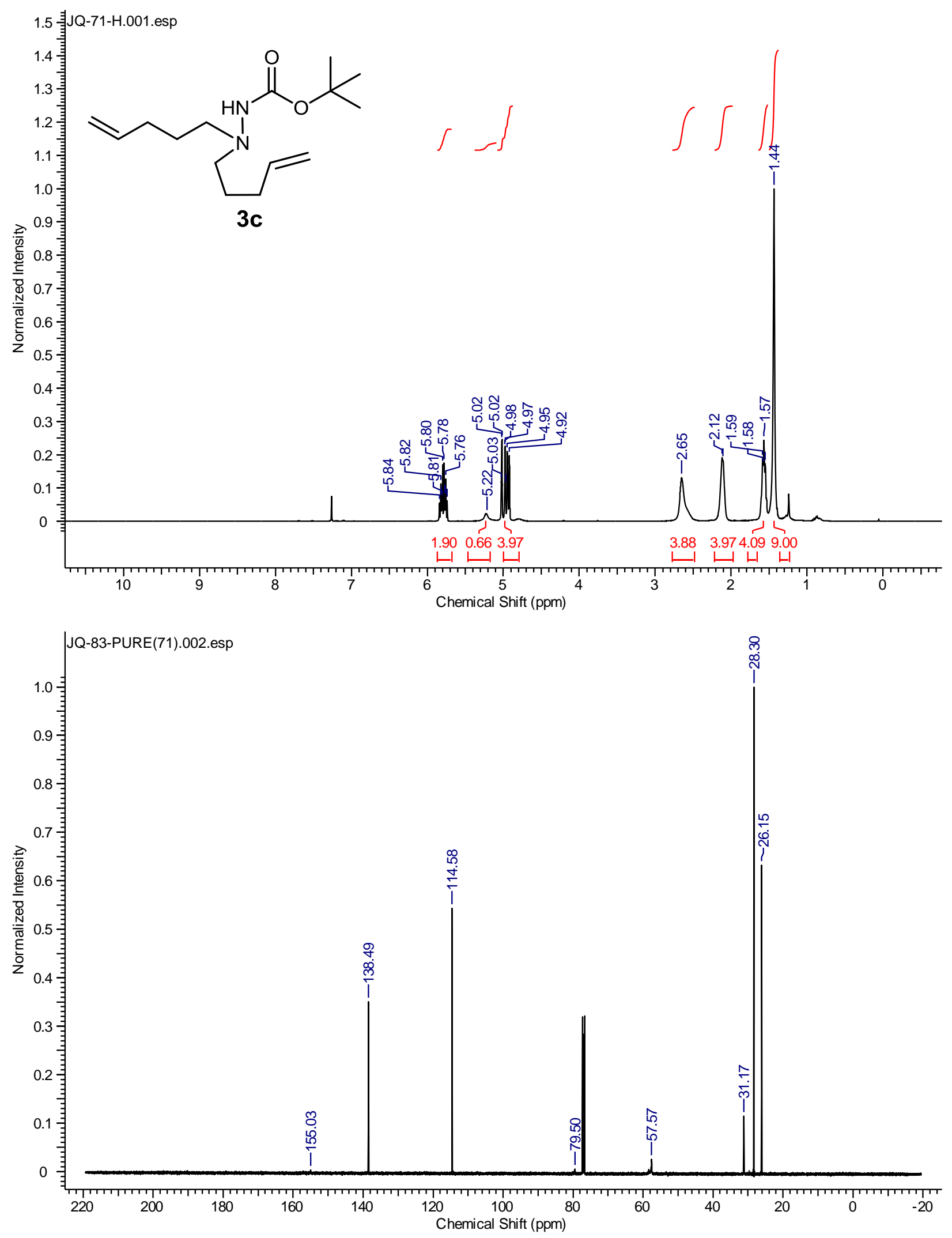

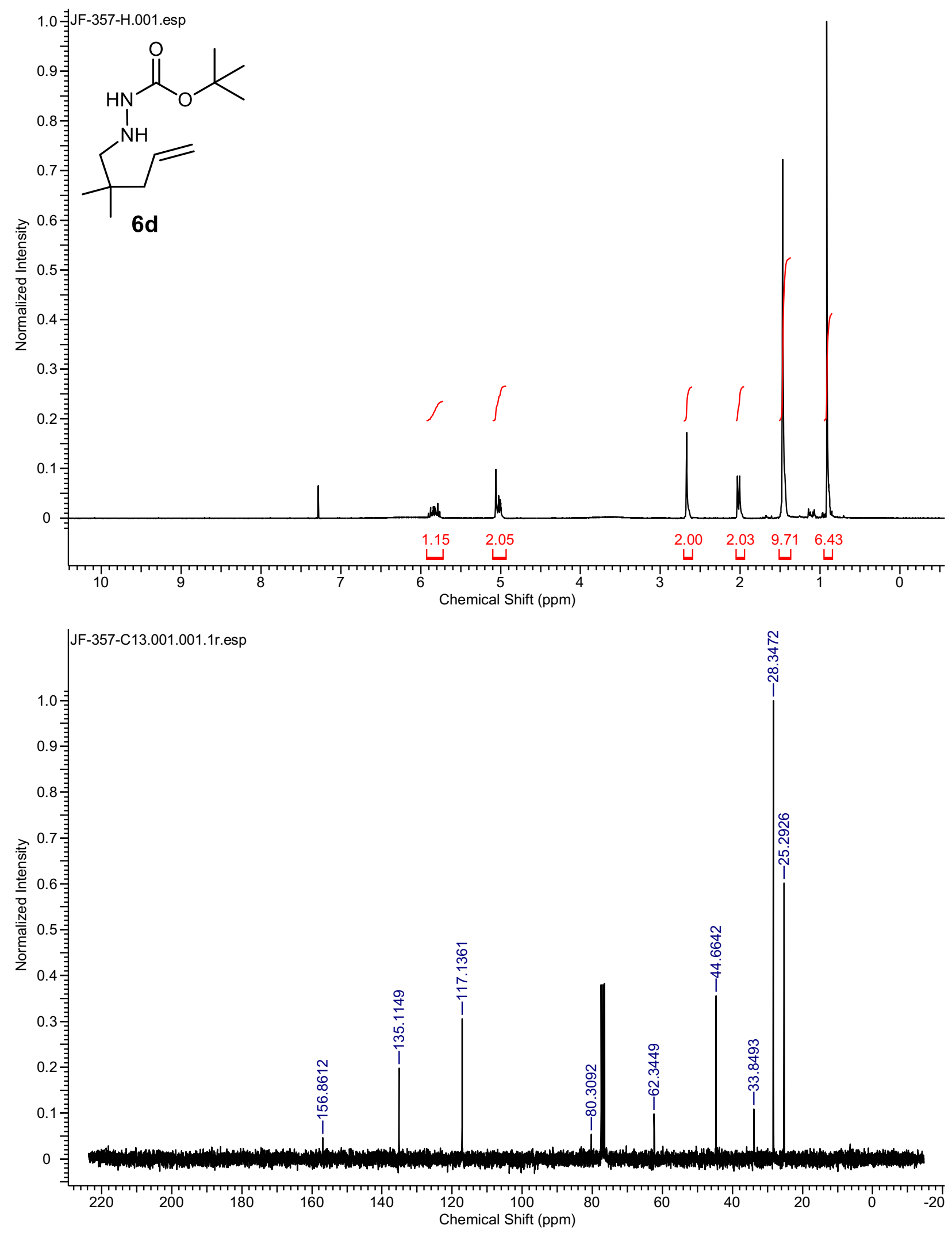

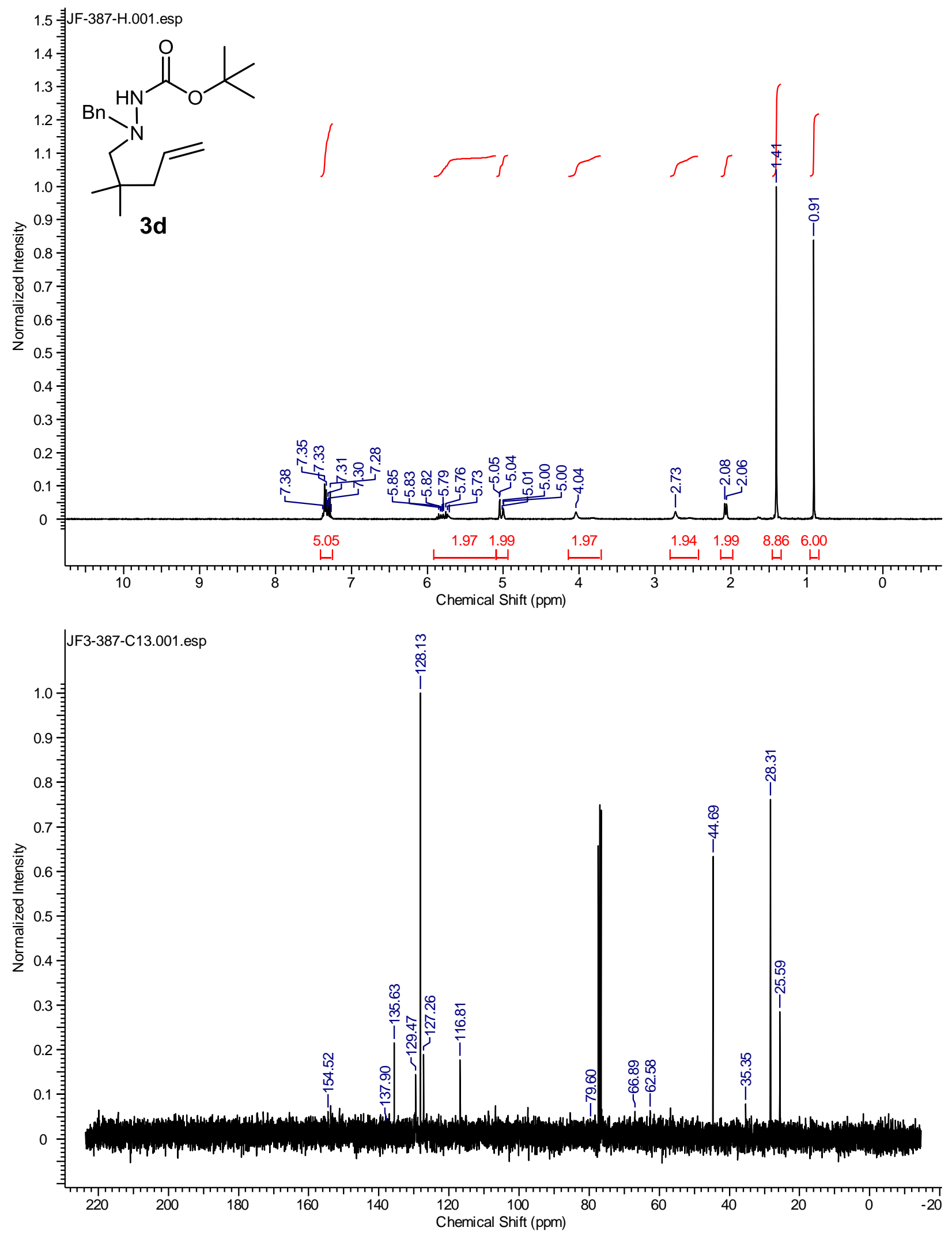

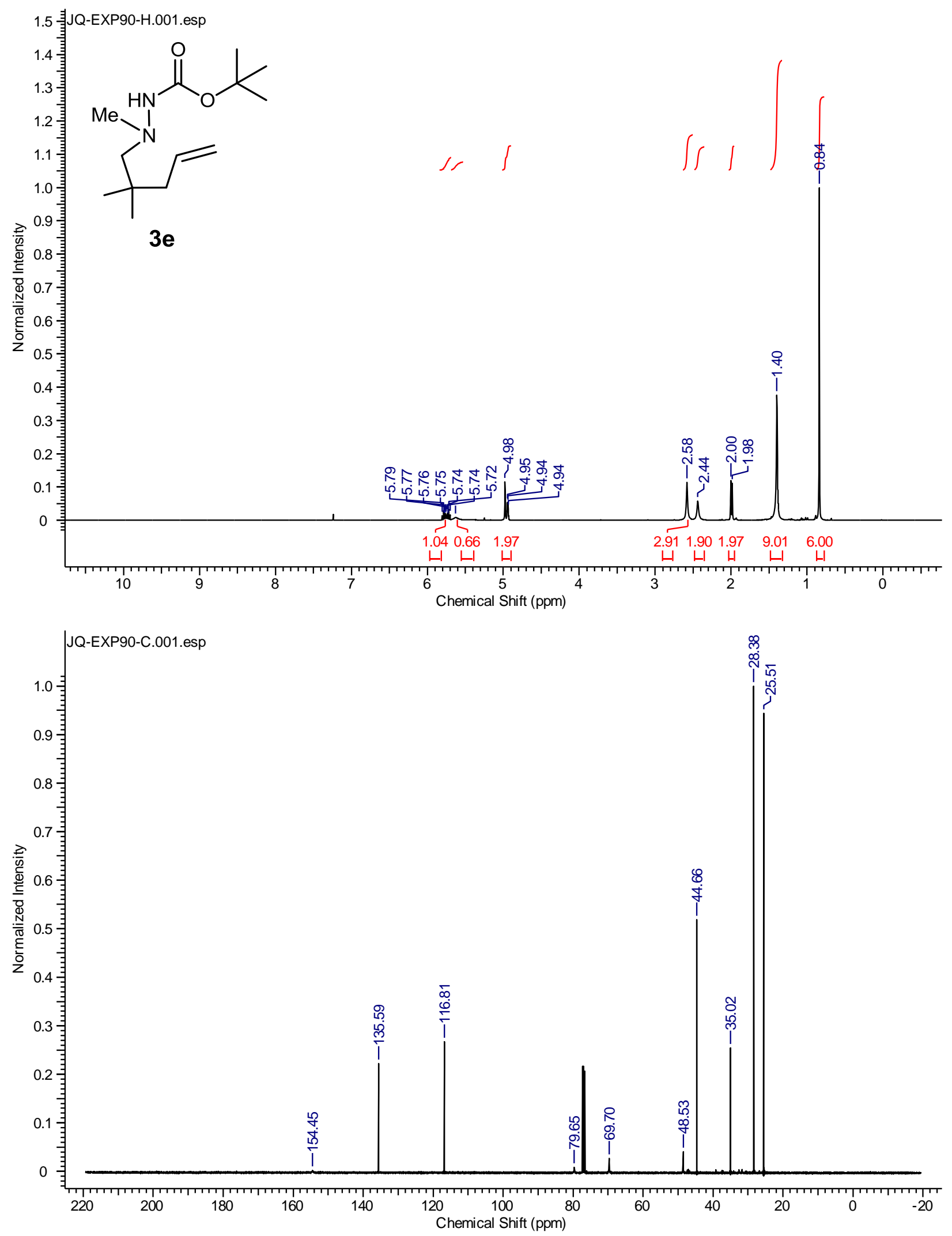

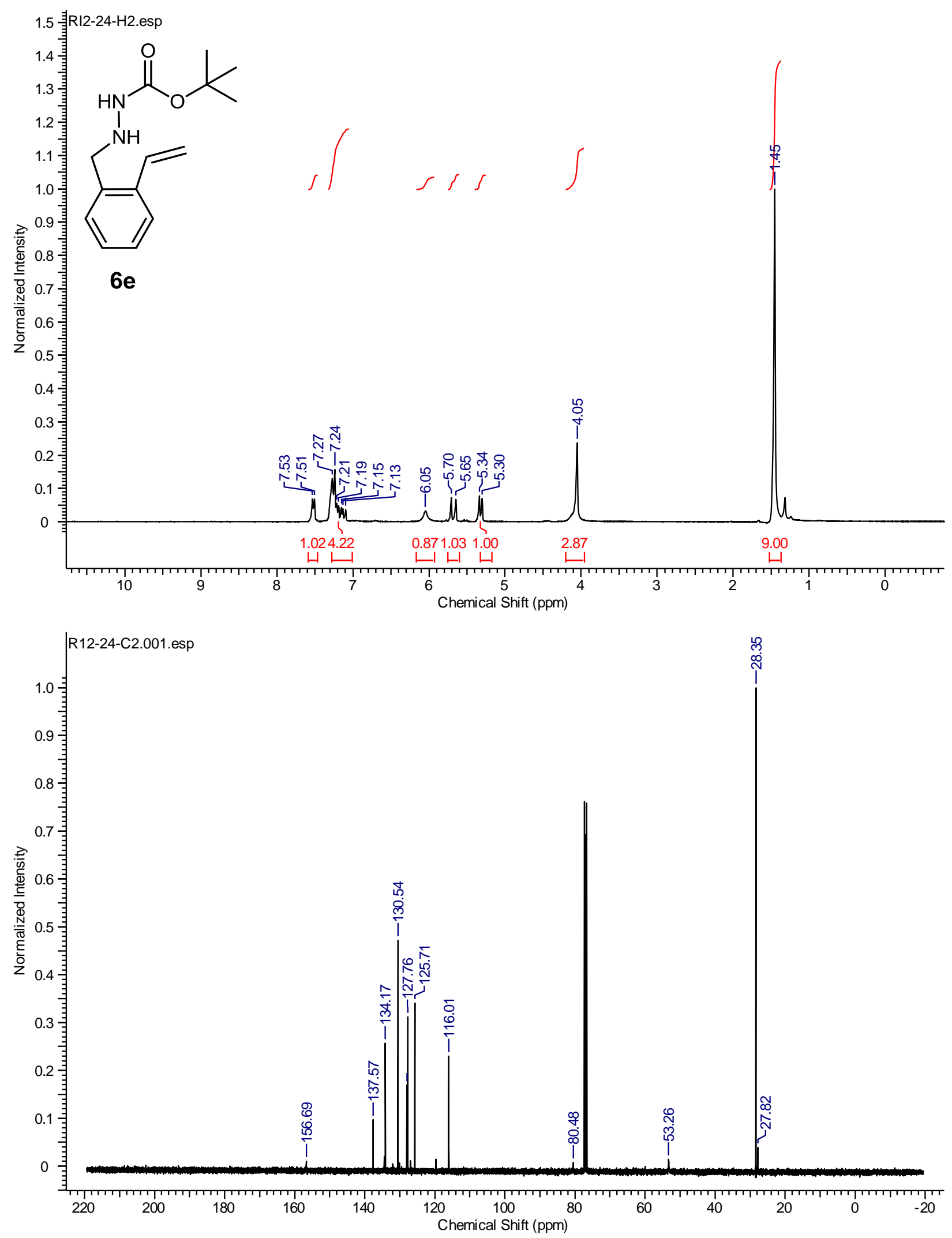

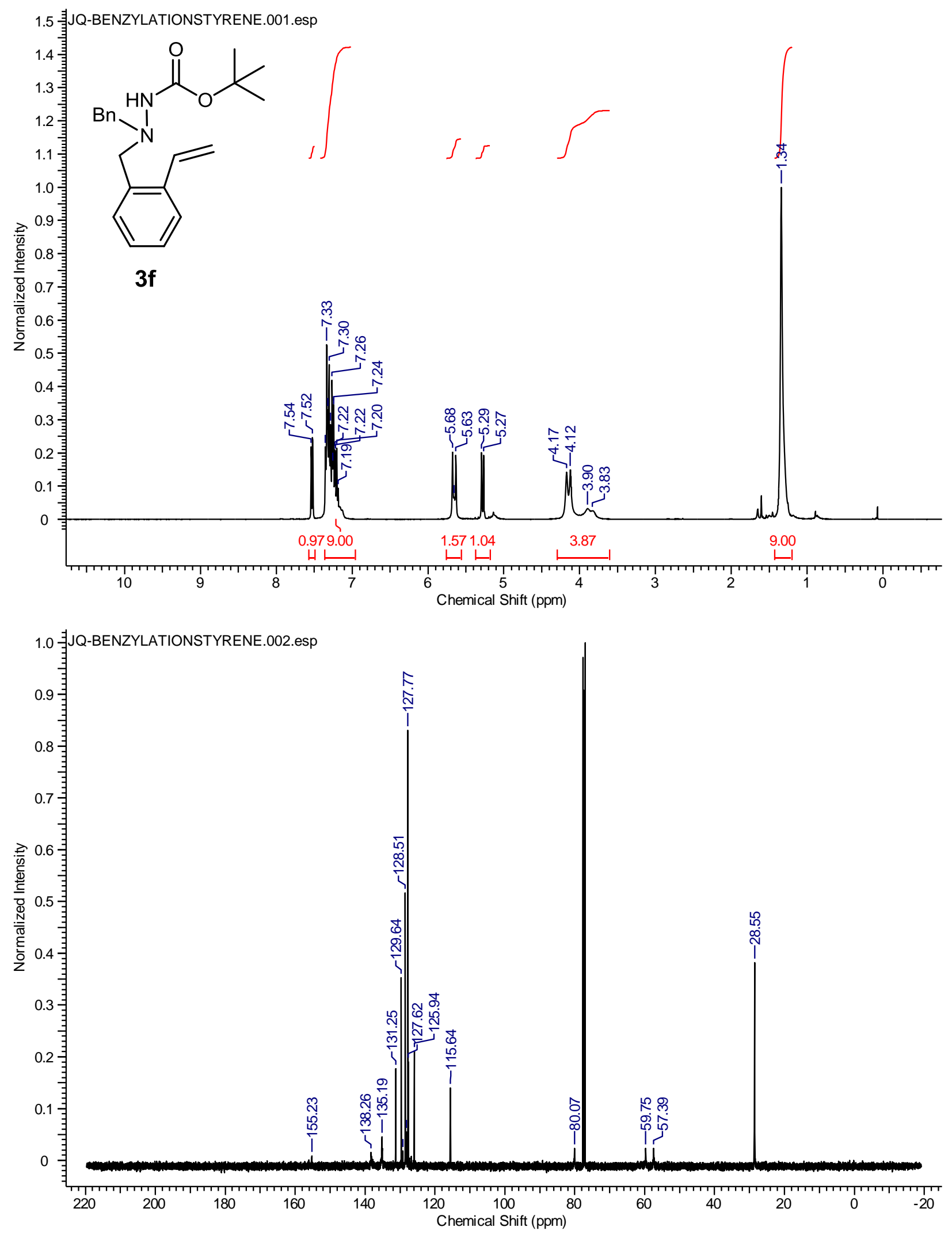

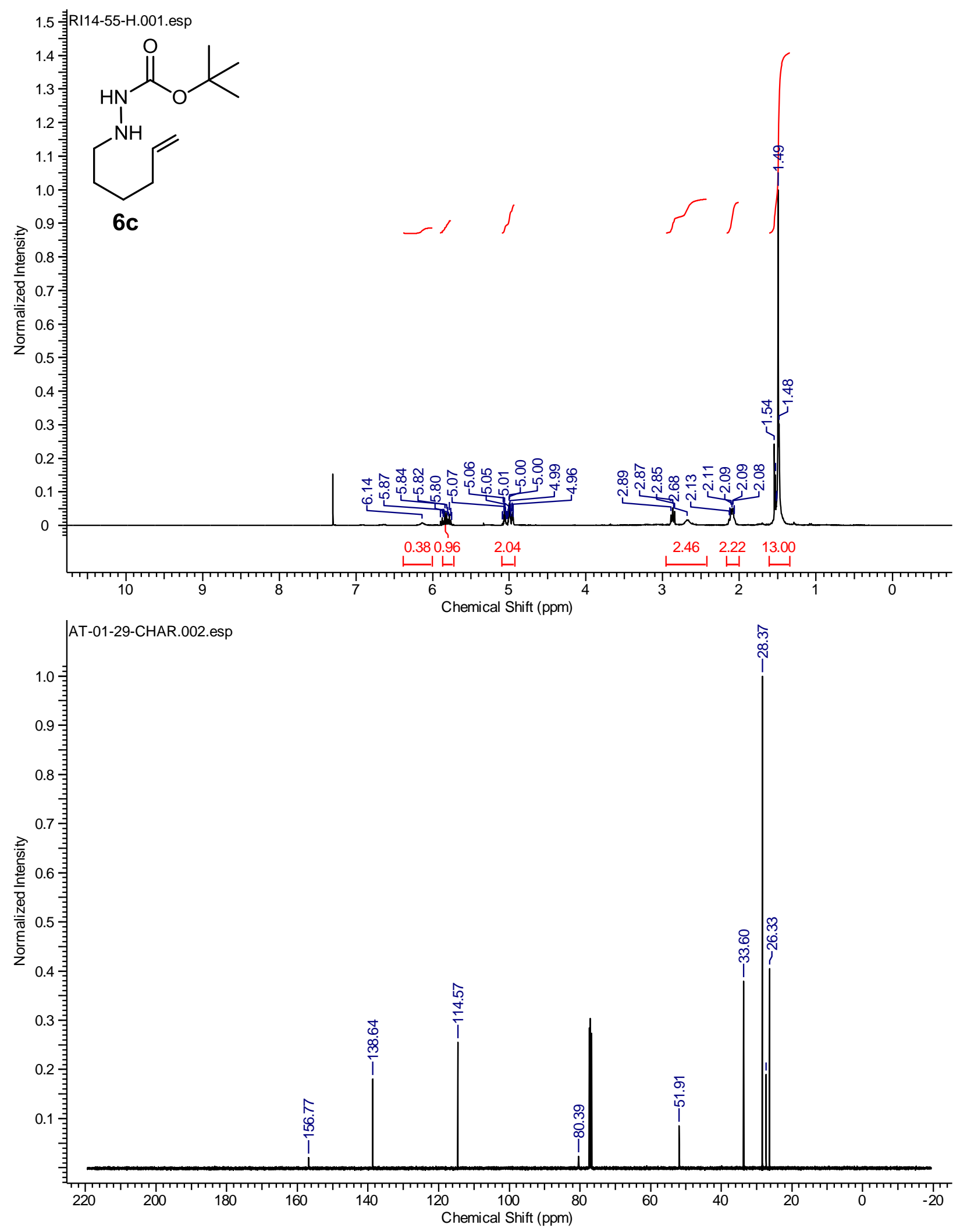

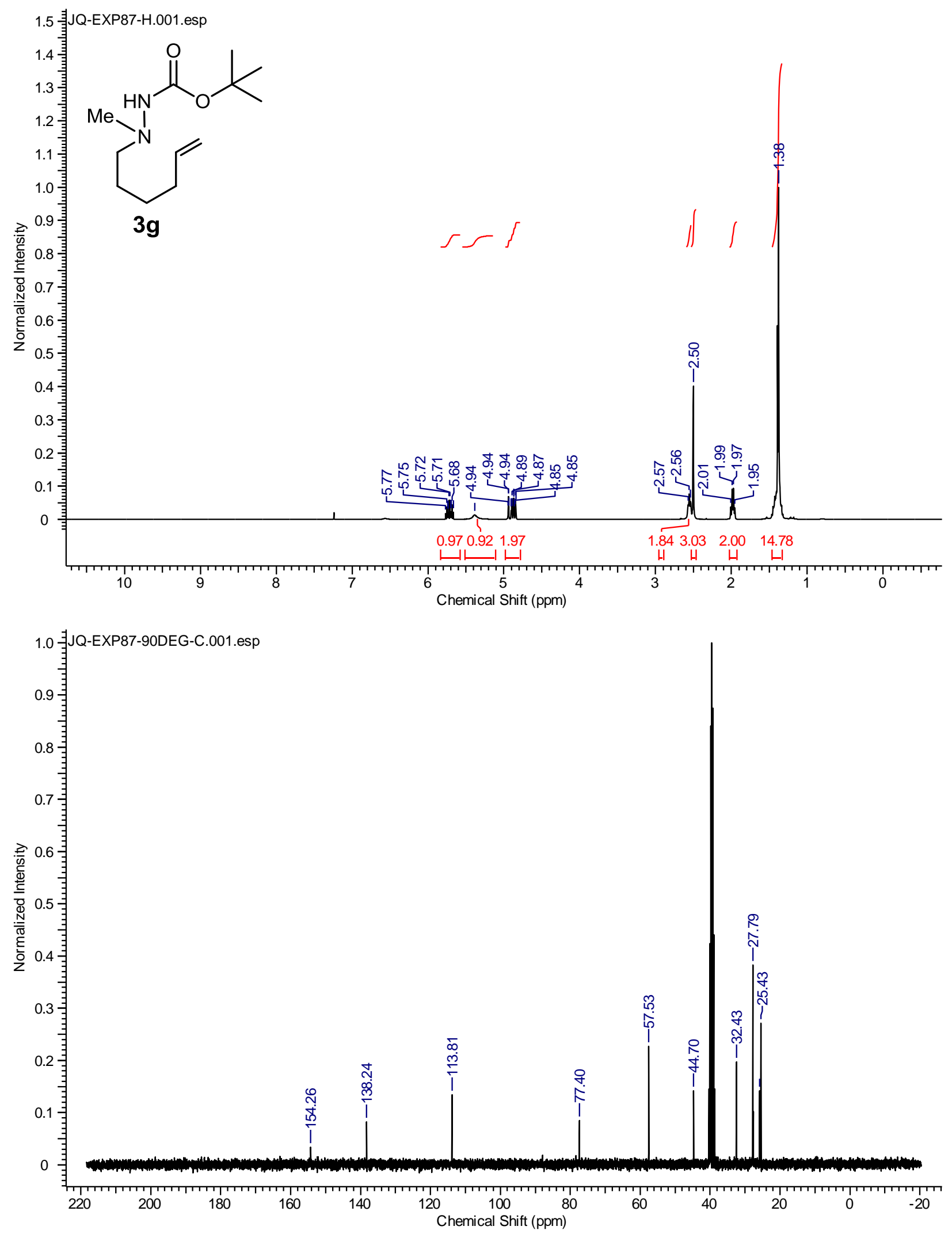

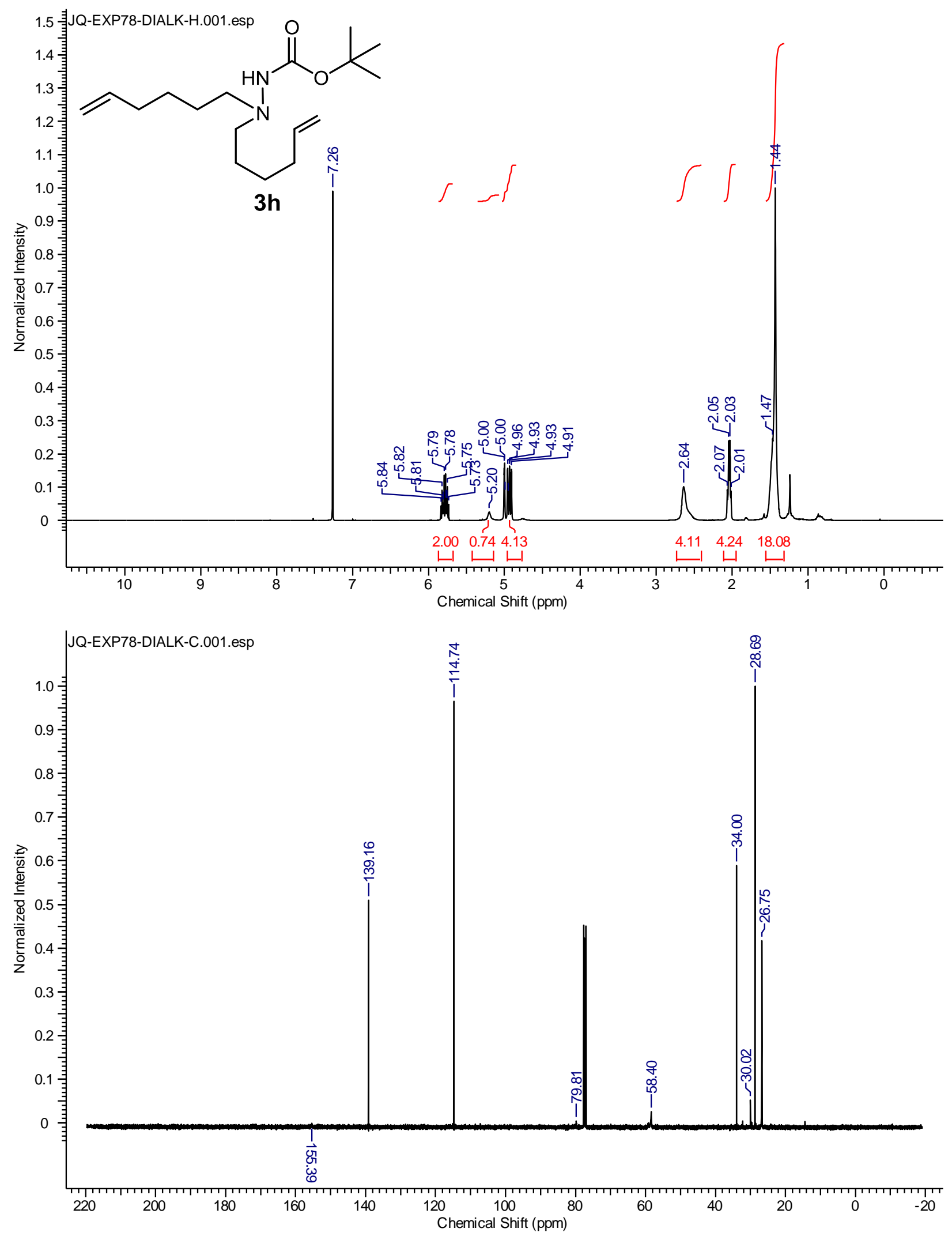

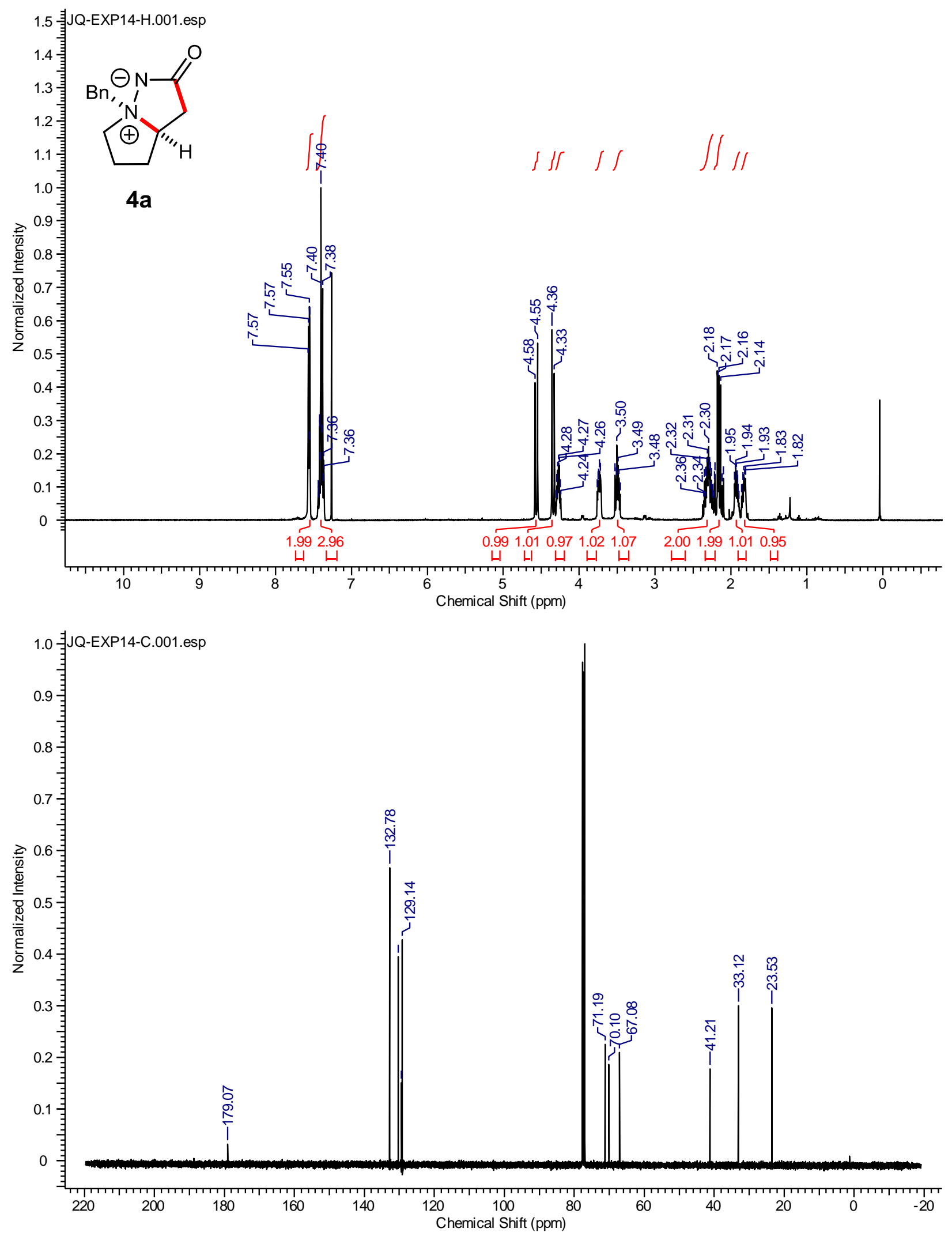

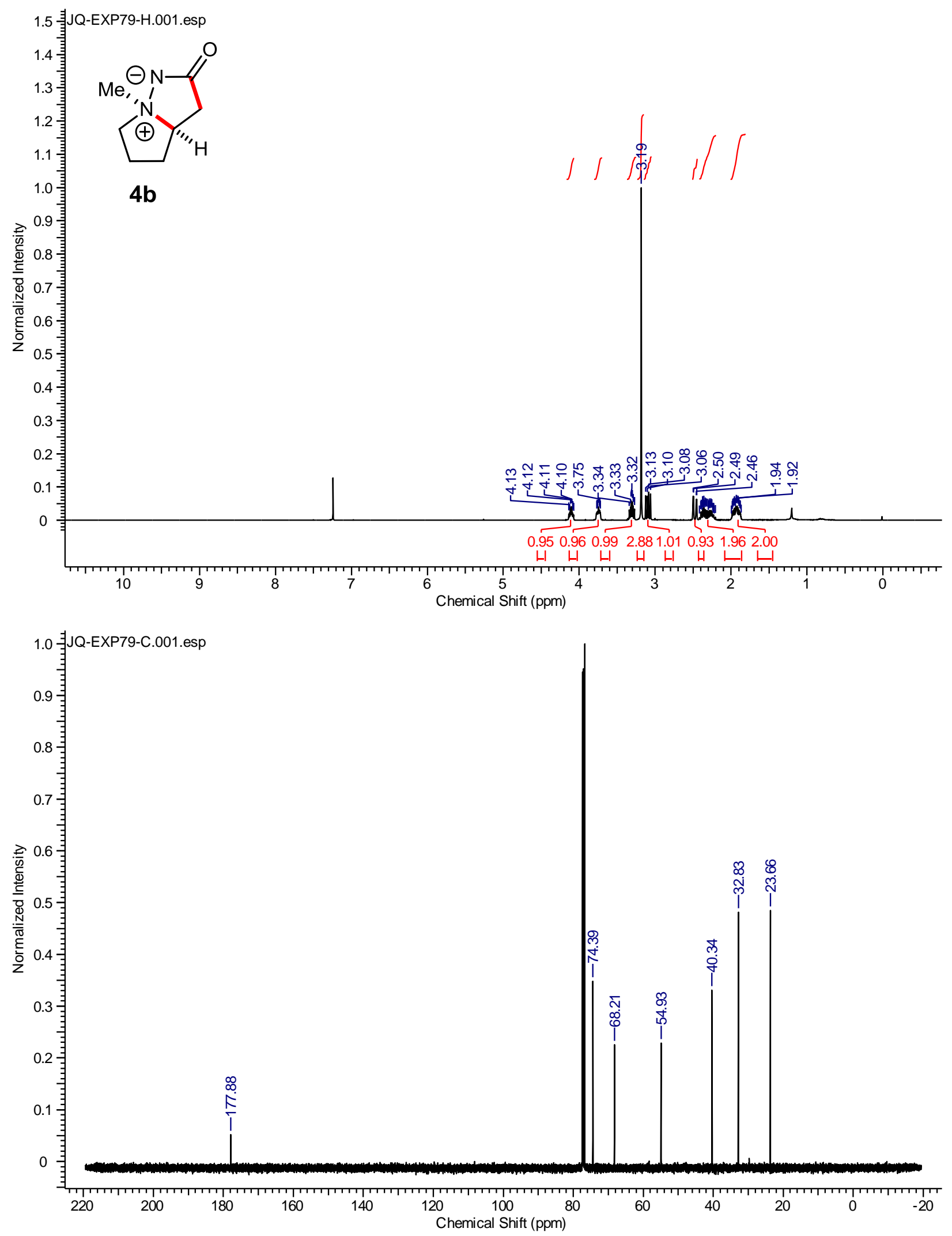

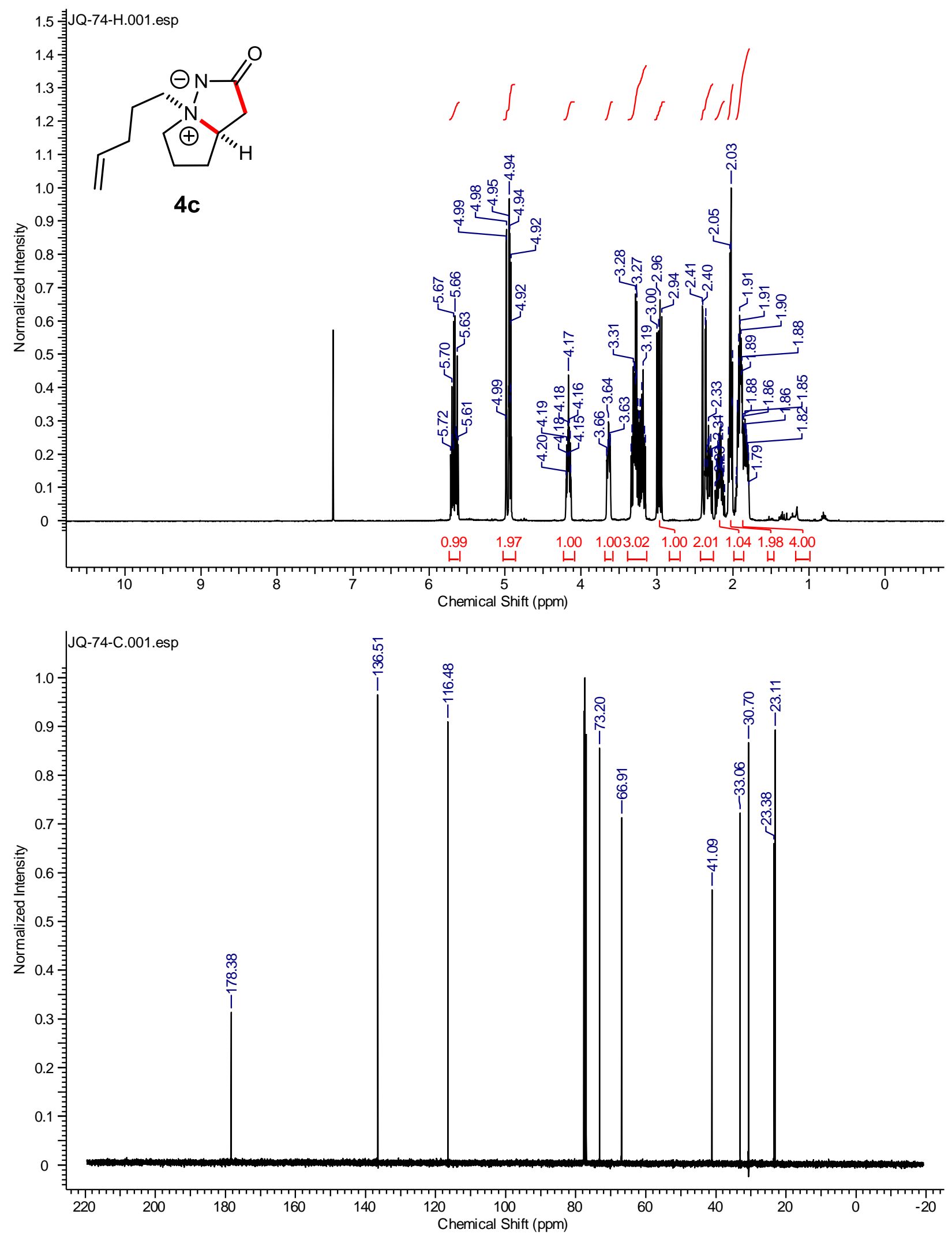

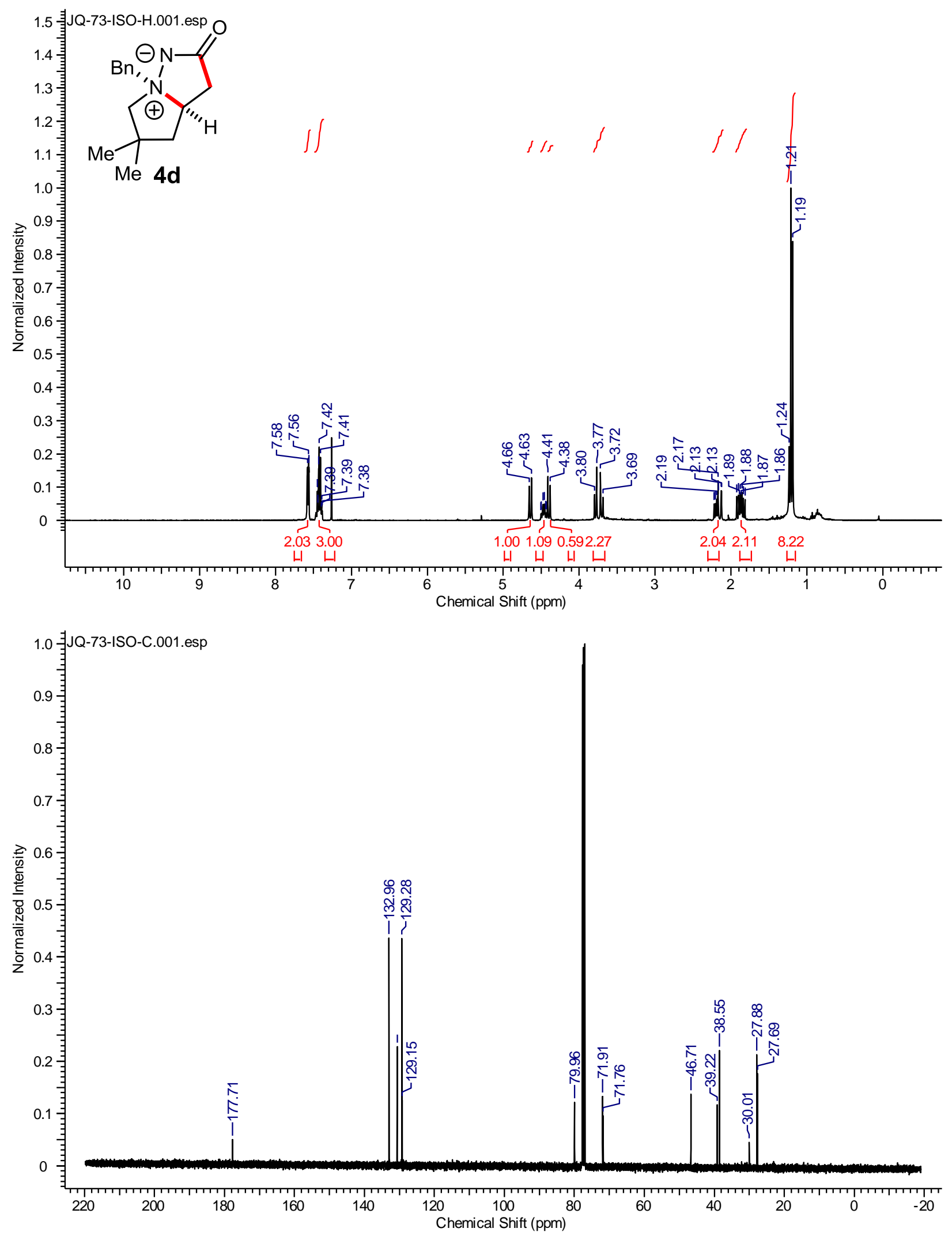

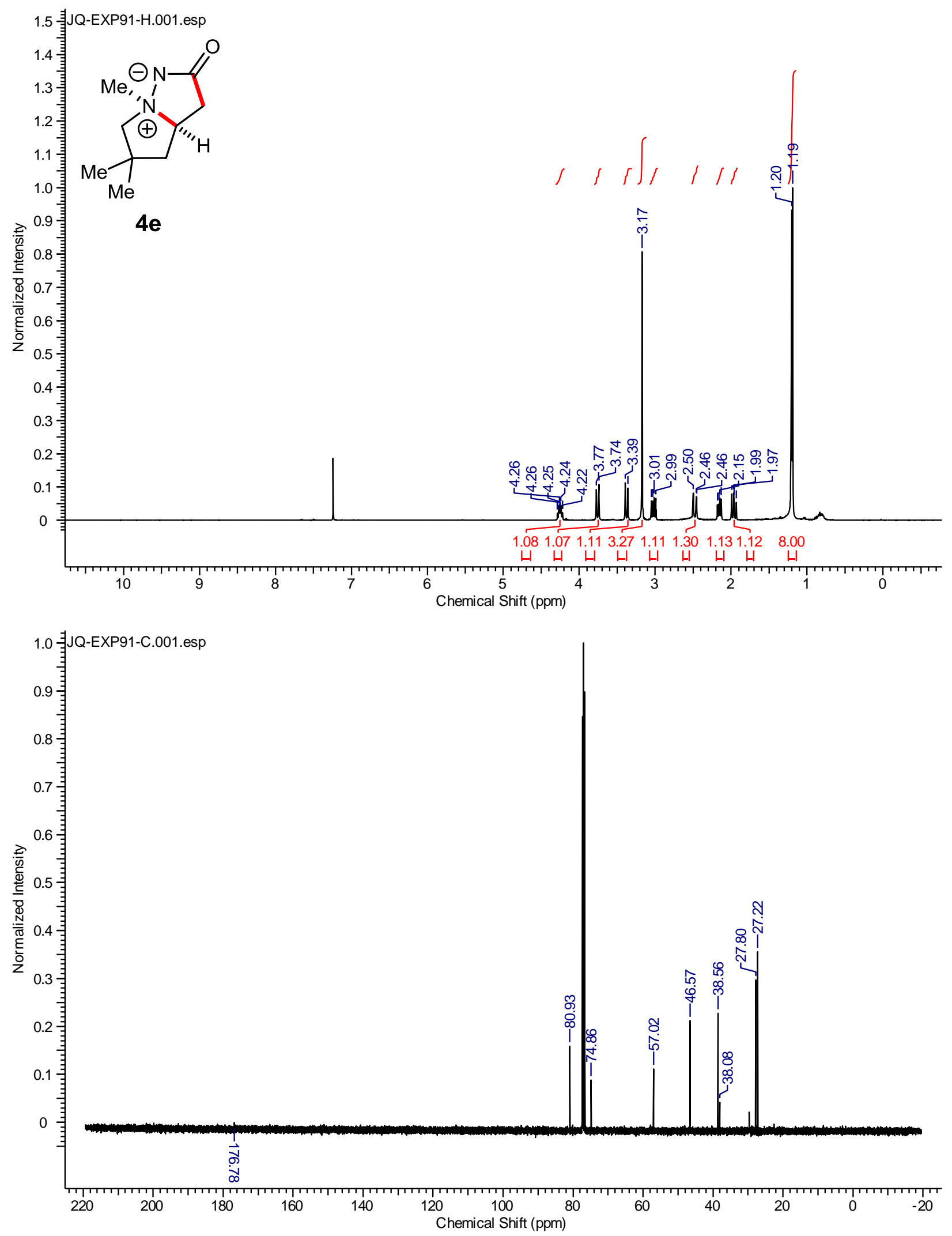

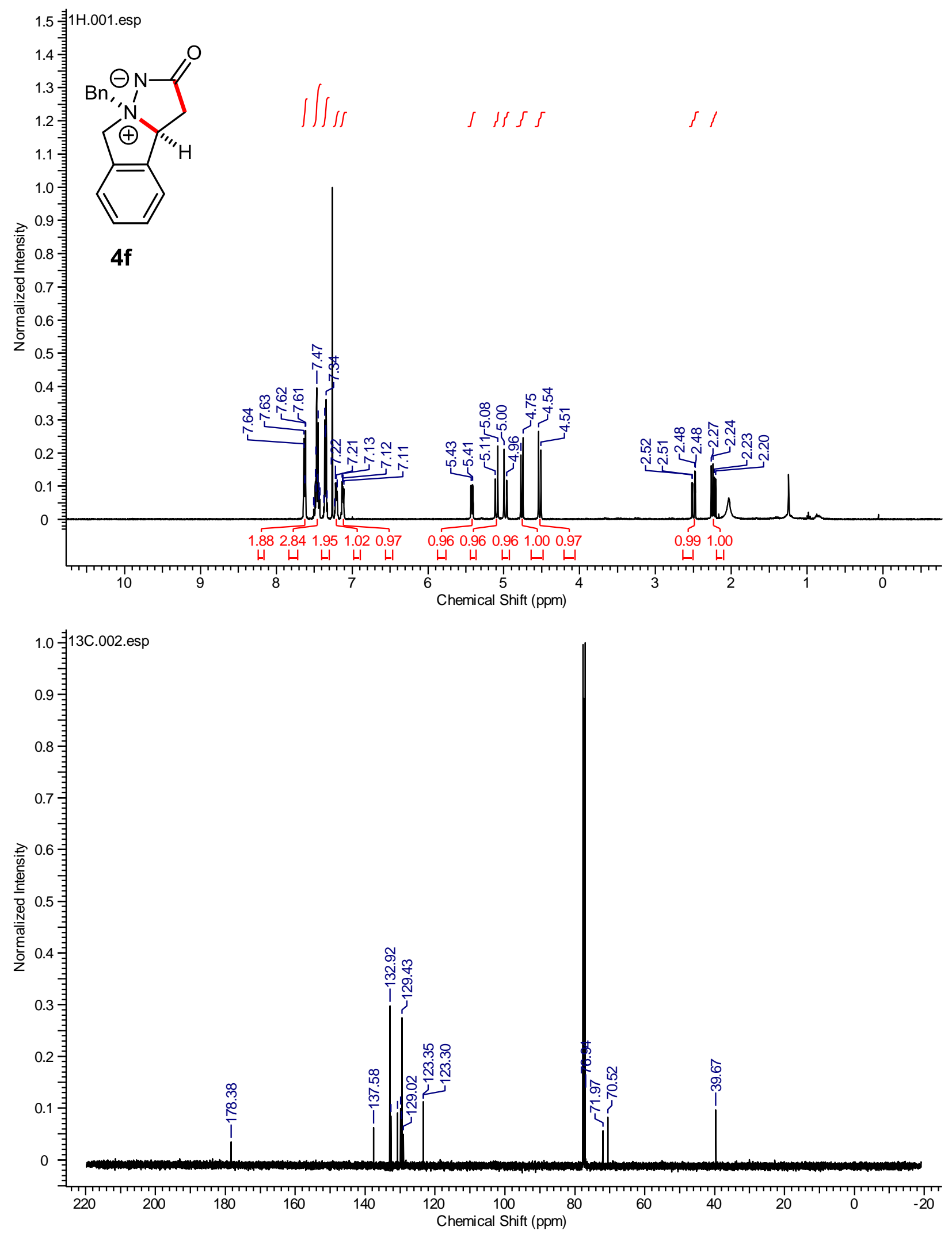

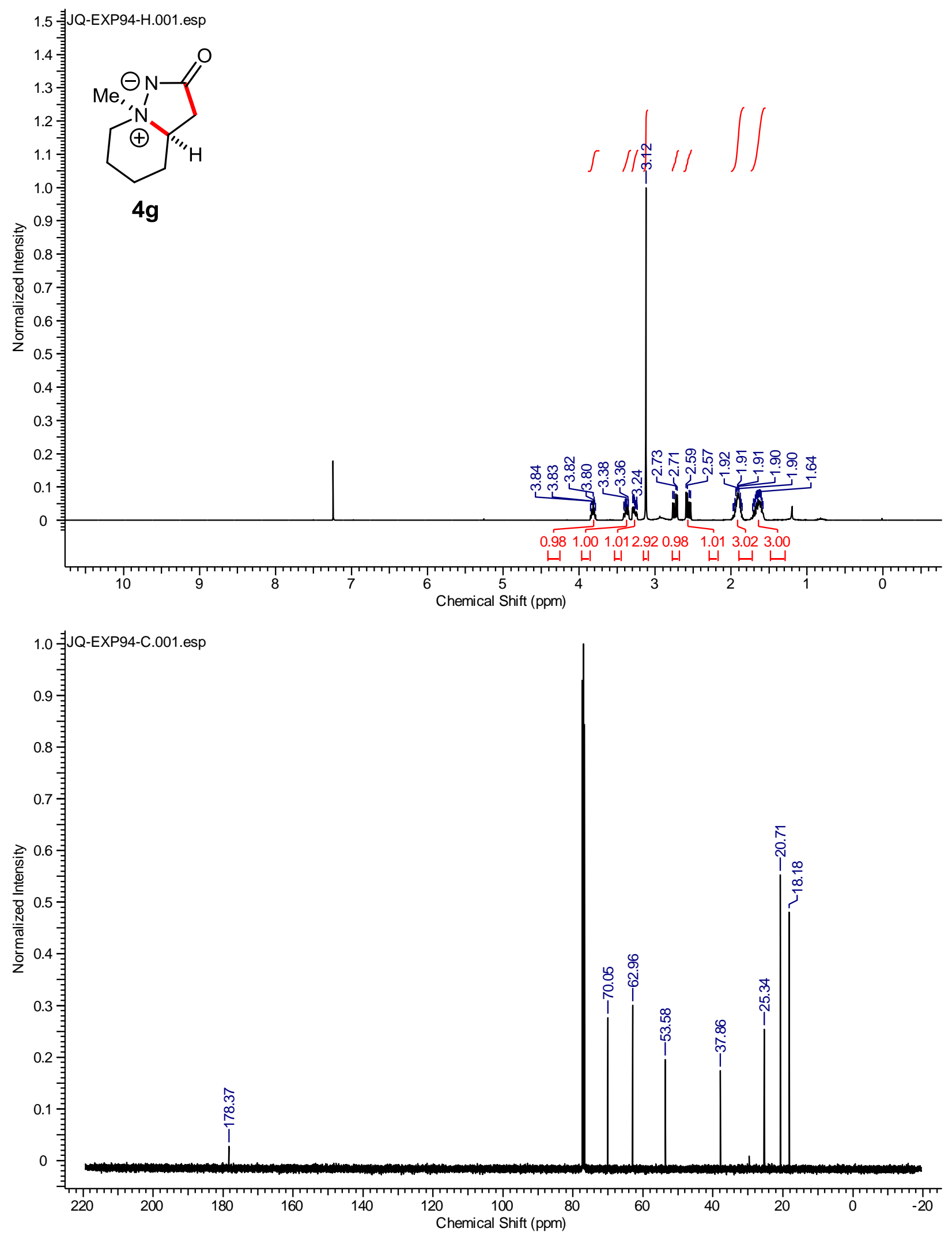

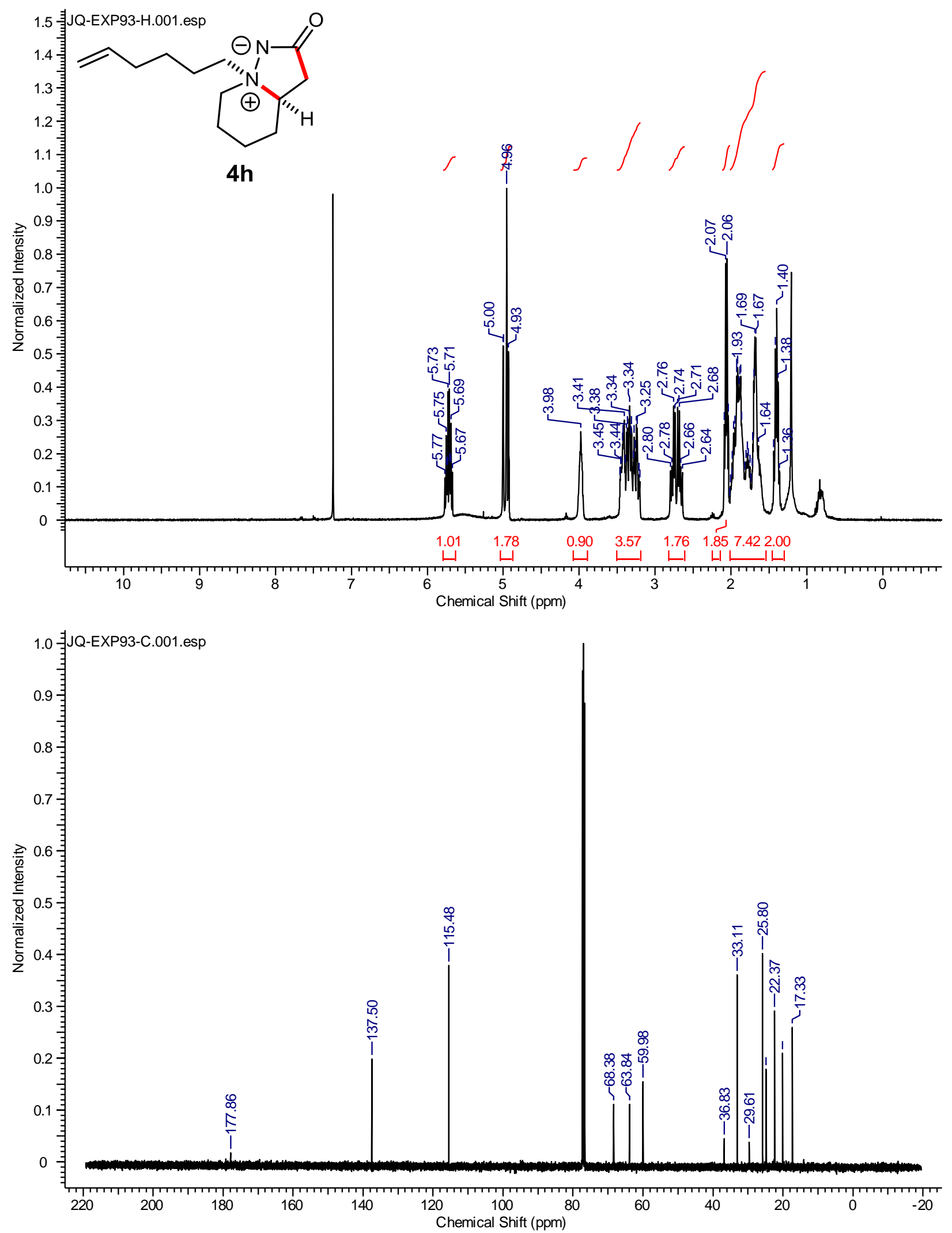

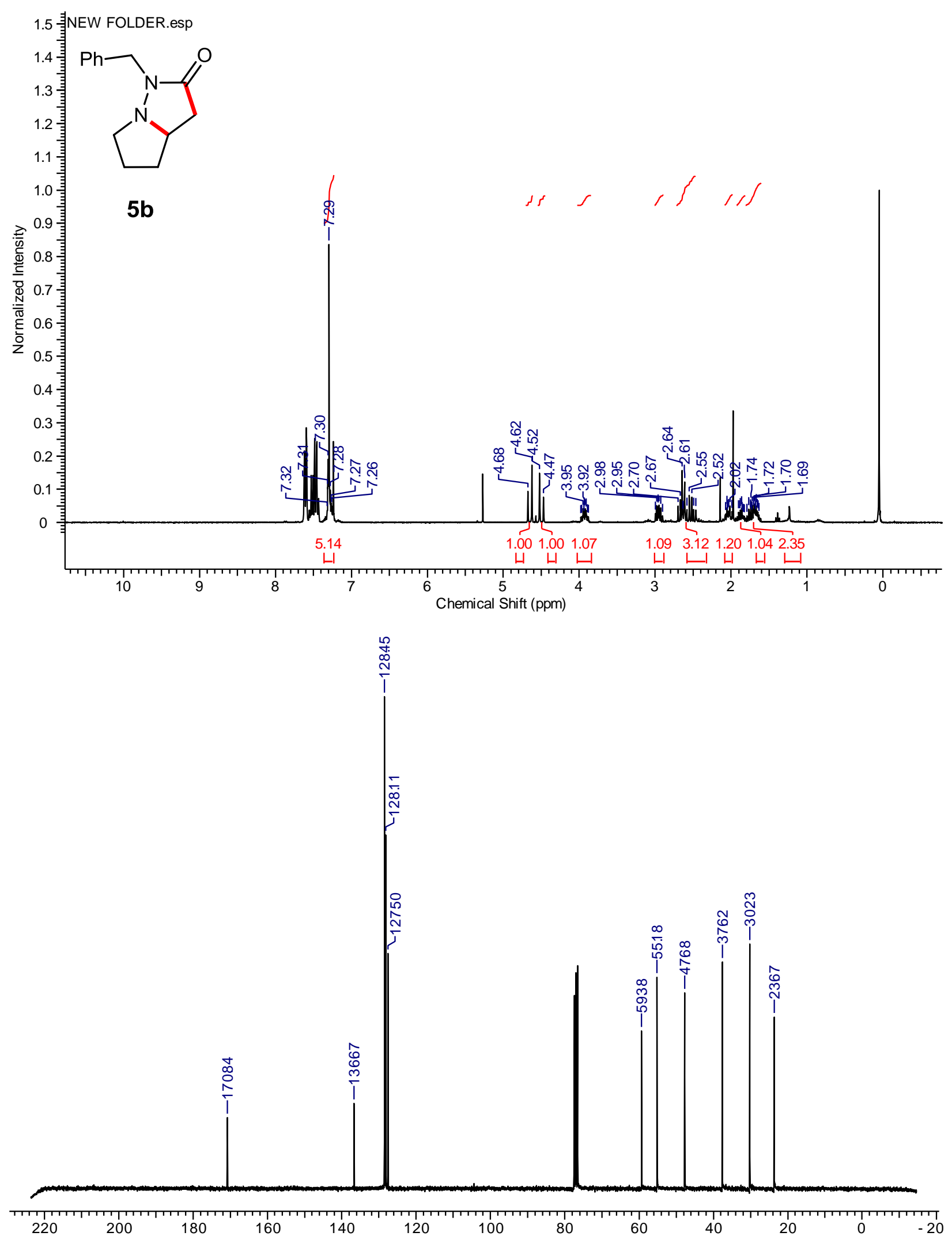
NOESY

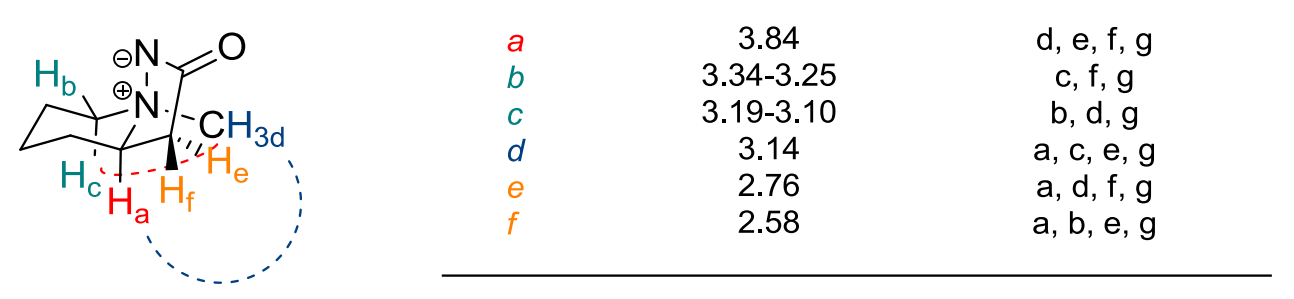

in red: ring junction proton. in blue: cis methyl substituent. in green: piperidine ring protons. in orange: pyrrolidine ring protons

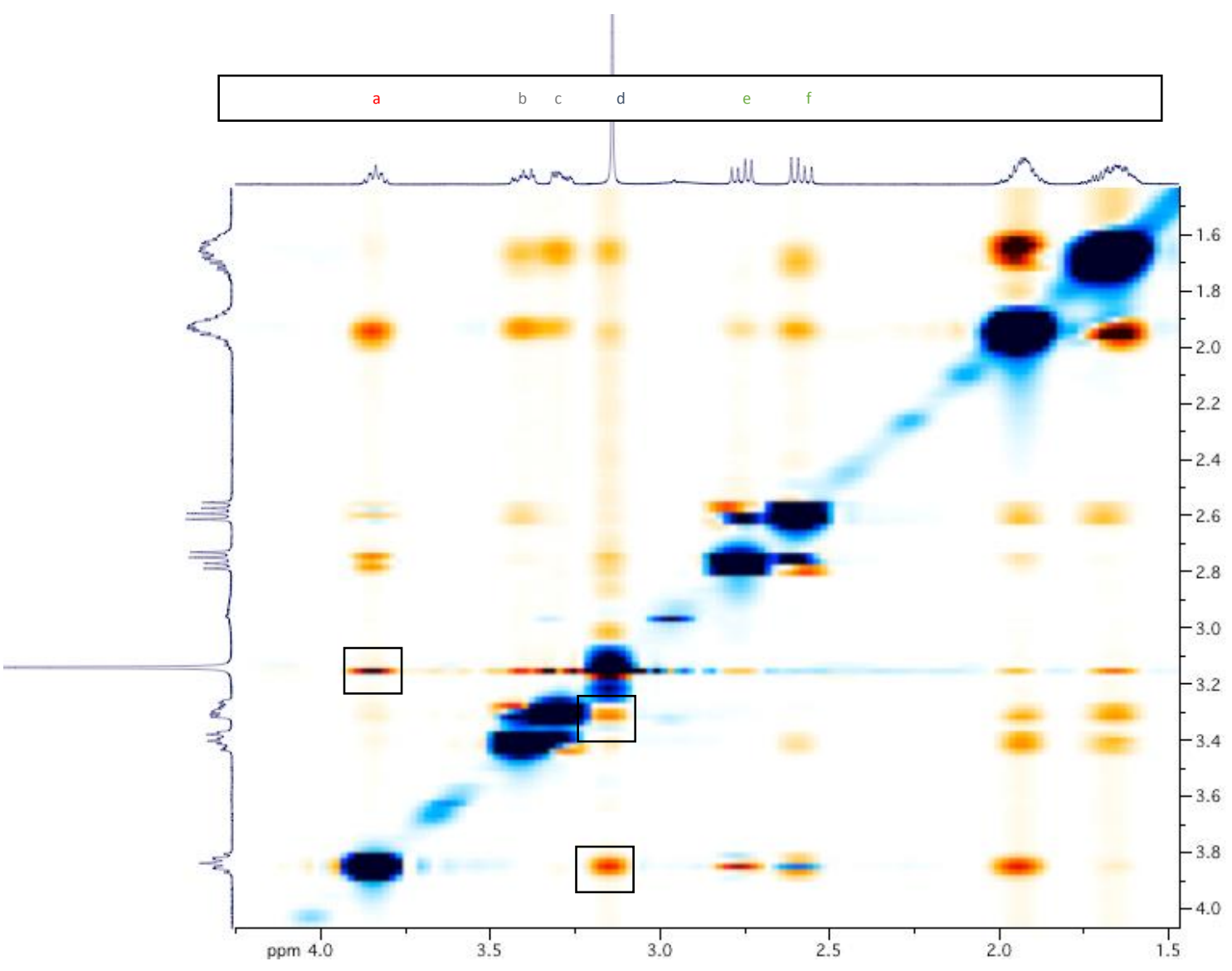




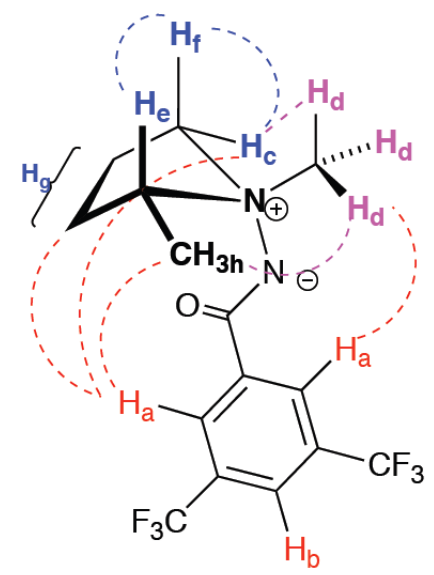

\begin{tabular}{ccc} 
Proton(s) & $\delta$ (ppm) & NOESY Interactions \\
\hline$a$ & 8.42 & $\mathrm{~b}, \mathrm{c}, \mathrm{d}, \mathrm{g}, \mathrm{h}$ \\
$\mathrm{b}$ & 7.79 & $\mathrm{a}$ \\
$c$ & $4.86-5.08$ & $\mathrm{a}, \mathrm{d}, \mathrm{f}, \mathrm{g}, \mathrm{h}$ \\
$d$ & 3.49 & $\mathrm{a}, \mathrm{c}, \mathrm{h}$ \\
$e$ & $3.33-3.48$ & $\mathrm{f}, \mathrm{g}, \mathrm{h}$ \\
$f$ & $3.14-3.31$ & $\mathrm{c}, \mathrm{e}, \mathrm{g}$ \\
$g$ & $1.85-2.25$ & $\mathrm{a}, \mathrm{c}, \mathrm{e}, \mathrm{f}, \mathrm{h}$ \\
$\boldsymbol{h}$ & 1.50 & $\mathrm{a}, \mathrm{c}, \mathrm{d}, \mathrm{e}, \mathrm{g}$ \\
\hline
\end{tabular}

in red: Benzoyl hydrazide protons. in purple: methyl substituent. in blue: pyrrolidine ring. in black: methyl substituent on the pyrrolidine ring.

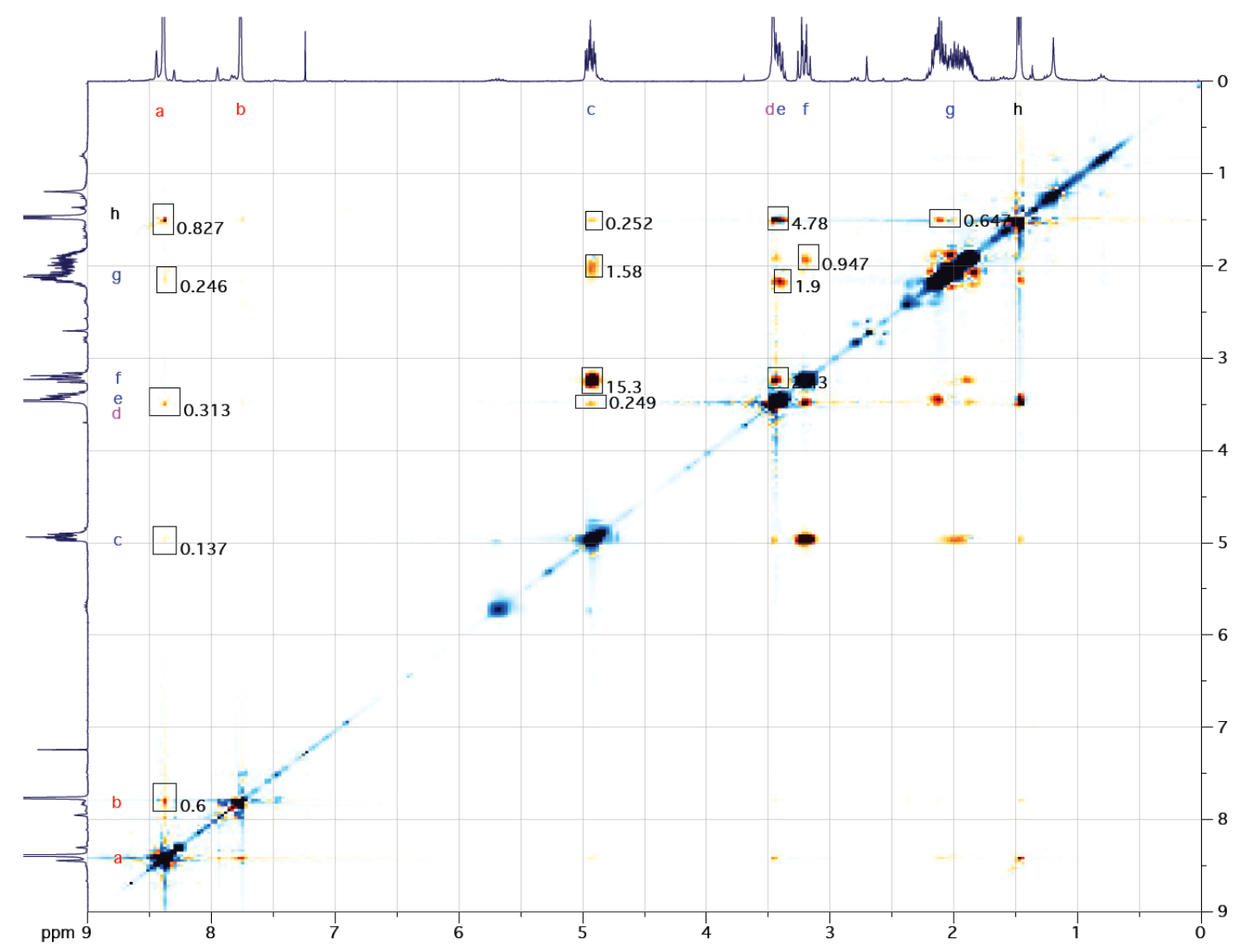



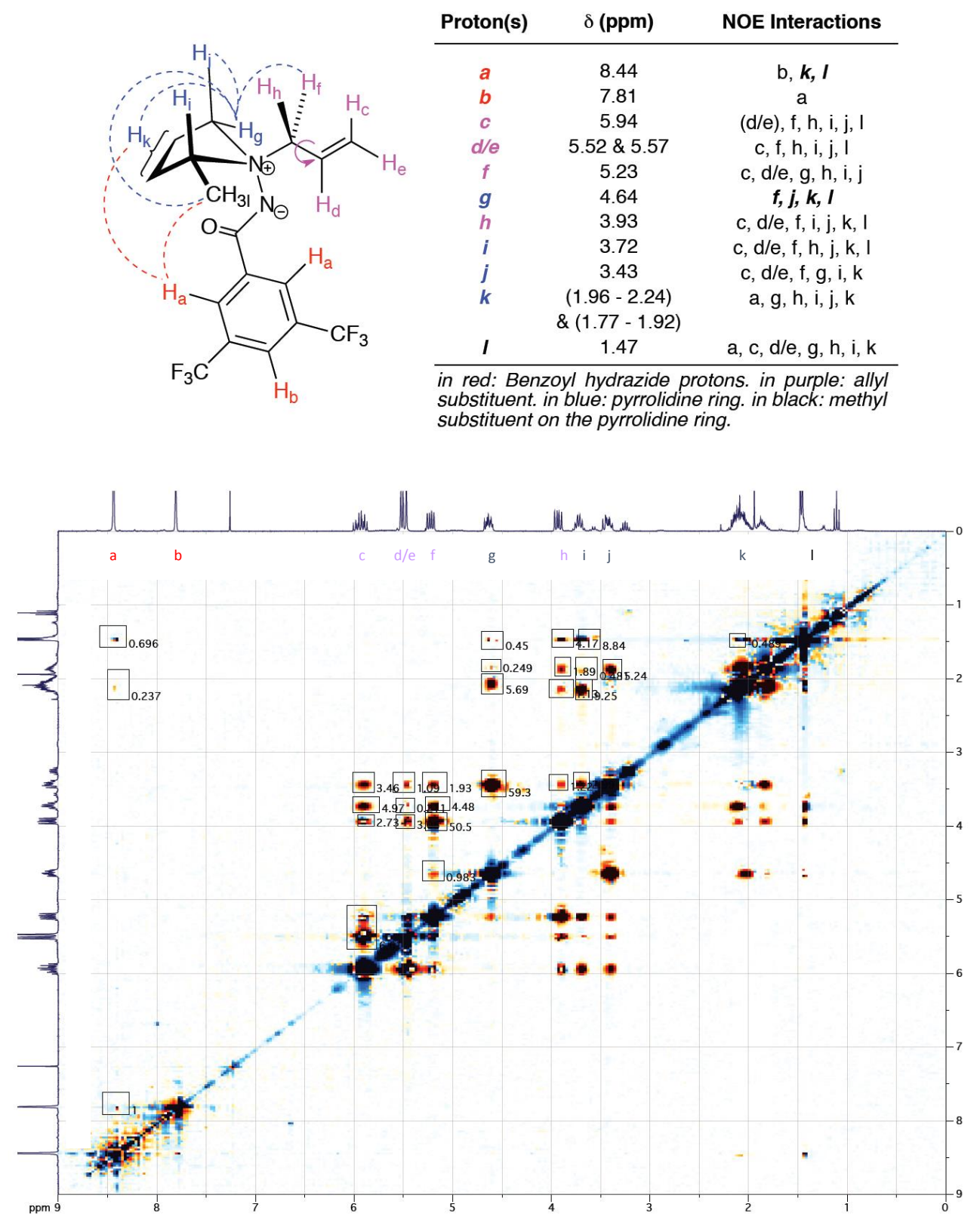